\title{
Gene Editing Technologies for Sugarcane Improvement: Opportunities and Limitations
}

\author{
Chakravarthi Mohan $^{1}$ (D) Mona Easterling ${ }^{2,3} \cdot$ Yuan-Yeu Yau $^{2}$
}

Received: 14 March 2020/Accepted: 7 August 2021/Published online: 15 October 2021

(C) Society for Sugar Research \& Promotion 2021

\begin{abstract}
Plant-based biofuels present a promising alternative to depleting non-renewable fuel resources. One of the benefits of biofuel is reduced environmental impact, including reduction in greenhouse gas emission which causes climate change. Sugarcane is one of the most important bioenergy crops. Sugarcane juice is used to produce table sugar and first-generation biofuel (e.g., bioethanol). Sugarcane bagasse is also a potential material for second-generation cellulosic biofuel production. Researchers worldwide are striving to improve sugarcane biomass yield and quality by a variety of means including biotechnological tools. This paper reviews the use of sugarcane as a feedstock for biofuel production, and gene manipulation tools and approaches, including RNAi and genome-editing tools, such as TALENs and CRISPR-Cas9, for improving its quality. The specific focus here is on CRISPR system because it is low cost, simple in design and versatile compared to other genome-editing tools. The advance of CRISPR-Cas9 technology has transformed plant research with its ability to precisely delete, insert or replace genes in recent years. Lignin is the primary
\end{abstract}

Chakravarthi Mohan

chakra3558@gmail.com

$\bowtie$ Yuan-Yeu Yau

academicfy1@gmail.com

Mona Easterling

mona.easterling@tulsacc.edu

1 Department of Genetics and Evolution, Federal University of São Carlos, São Carlos, Brazil

2 Department of Natural Sciences, Northeastern State University, Broken Arrow, OK 74014, USA

3 Northeast Campus, Tulsa Community College, 3727 East Apache St, Tulsa, OK 74115, USA material responsible for biomass recalcitrance in biofuel production. The use of genome editing technology to modify lignin composition and distribution in sugarcane cell wall has been realized. The current and potential applications of genome editing technology for sugarcane improvement are discussed. The advantages and limitations of utilizing RNAi and TALEN techniques in sugarcane improvement are discussed as well.

Keywords Bioenergy - Biofuel · CRISPR-Cas9 · Genome editing - Lignocellulosic feedstock · RNAi . Sugarcane $\cdot$ TALENs

\section{Introduction}

The anticipated depletion and, more significantly, the negative environmental impacts of non-renewable fossil fuels necessitate the utilization of alternative energy sources. Biofuels are becoming an important part of transportation fuel globally and they are produced through processes that discharge significantly fewer pollutants (Fargioni et al. 2008) including greenhouse gases into the environment. Biofuels can be produced from three different sources. They are starch, sugar and oil from food and other grains and sugarcane juice (first-generation biofuels), lignocellulosic biomass from sugarcane bagasse, wood and straw or other suitable biomass (second-generation biofuels) and algae (third-generation biofuels) (Jeswani et al. 2020). Lignocellulosic feedstocks constitute the largest renewable resource with an annual production of $150 \times 10^{9}-170 \times 10^{9}$ tonnes (Pauly and Keegstra 2008). Potential second-generation dedicated energy crops include Miscanthus spp. (elephant grass) and Switchgrass (Panicum virgatum L.). Bioethanol is currently the most 
common biofuel produced worldwide (Araujo et al. 2017). The United States (USA) and Brazil are the largest bioethanol producers in the world. While USA largely uses corn, Brazil utilizes sugarcane juice as feedstock for bioethanol production.

Certain attributes are considered important for an ideal energy crop. These traits include fast growth, high yield, reduced inputs (e.g., fertilizer, water), low processing cost and high positive energy balance (Waclawovsky et al. 2010). Currently, the only crop displaying all of the listed characteristic traits is sugarcane. Sugarcane (Saccharum spp. hybrids), a perennial crop, has been widely cultivated in tropical and subtropical regions of the world for sugar and bioethanol production. Being a $\mathrm{C} 4 \mathrm{crop}$, sugarcane possesses the highest solar energy conversion efficiency and highest biomass yield among all agricultural crops (Henry 2010). Sugarcane stalks constitute about $80 \%$ of the total biomass, and the total above-ground dry biomass yield can reach more than 39 tonnes/hectare per year (Heaton et al. 2008).

Increase in biomass yield and its quality can be directly proportional to increase in sugar and bioethanol production. Improved biomass yield can be achieved through targeted breeding. Also, recent advances in sugarcane molecular marker technologies offer additional tools for breeders to improve sugarcane for bioenergy production. For example, researchers have identified important molecular markers and QTLs associated with sugarcane biomass traits and they are being evaluated for sugarcane yield improvement (Hoarau et al. 2002; Aitken et al. 2005; Bilal et al. 2015; Racedo et al. 2016). Similarly, in another example, Vicentini et al. (2015) performed a transcriptome evaluation of two sugarcane genotypes contrasting for lignin content through RNA sequencing (RNA-seq). The sugarcane genotypes used are IACSP04-065 and IACSP04627. Average lignin content is $4.32 \%$ in genotype IACSP04-065 and 8.12\% in genotype IACSP04-627 (on a dry weight basis). Gene expression analysis of these clones showed that over 2000 transcripts were differentially expressed between the two genotypes, including several genes involved in lignin biosynthetic pathway. They identified 21 sugarcane transcripts that encode for enzymes involved in lignin biosynthesis. Those genes could be used as potential targets for overexpression or knockout through genetic engineering to study their biological role in lignin biosynthesis. In another case, Hoang et al. (2017) sequenced the transcriptome of sugarcane culm tissue and identified 151 transcripts that were directly related to sugar and fiber metabolism. Thus, combining the knowledge of gene expression and QTLs, including expression QTL (eQTL, a locus that explains a fraction of the genetic variance of a gene expression phenotype.), helps develop strategies to improve sugarcane traits in the near future (Carrasco-Valenzuela et al. 2019).

The advent of genome-editing technologies, especially CRISPR, in recent years has paved the way for crop trait improvement in a rapid and efficient manner. However, to effectively use CRISPR technology, prior knowledge of genomic sequences is required. Unfortunately, the complex genome and high polyploidy nature of sugarcane have prevented genome sequencing of this crop until recently (Riaño-Pachón and Mattiello 2017). Therefore, unlike other crops, the use of genome-editing tools, especially the RNA-guided nucleases (CRISPR), for gene editing in sugarcane is still in its infancy. The recent availability of sugarcane's genome sequence will undoubtedly facilitate research on functional genomics with this important cash crop. In this context, this paper reviews the possible applications of genome-editing tools, focusing on CRISPR technology, to study biomass and bioenergy traits in sugarcane. The limitations of its use are also discussed. In addition, another important biotechnological advance on biomass improvement using RNA interference (RNAi) technique is also discussed.

\section{Sugarcane}

Sugarcane belongs to the Saccharum genus which includes Saccharum barberi, Saccharum edule, Saccharum officinarum, Saccharum robustum, Saccharum sinense and Saccharum spontaneum. They are genetically closely related to sorghum and other Poaceae members such as Erianthus and Miscanthus (Amalraj and Balasundaram 2006). As a result of interspecific hybridization, modern sugarcane varieties (Saccharum spp) possess high polyploidy and aneuploidy. Sugarcane has an estimated genome size of $\sim 10 \mathrm{Gbp}$, with genes exist up to 10-12 allelic forms (Souza et al. 2011). The estimated monoploid genome size is about $800-900 \mathrm{Mb}$, depending on the ploidy level of a variety (Garsmeur et al. 2018).

\section{Sugarcane as Biofuel Feedstock}

Being a $\mathrm{C} 4$ crop, sugarcane is considered to be one of the most ideal bioenergy crops. Sugarcane is nearly the exclusive ethanol feedstock in some countries such as Brazil. Brazil produced 32.5 billion liters of sugarcane ethanol in 2019-2020 (http://sugarcane.org/sugarcane products/ethanol). It is currently the largest sugarcane ethanol producer in the world. Brazil and USA together account for $85 \%$ of the world's ethanol production (Bertrand et al. 2016). The general process of ethanol production from sugarcane is illustrated in Fig. 1. 
Sugarcane is one of the main feedstocks for first- and second-generation biofuel production. Sugarcane bagasse constitutes $25 \%$ of the total weight of sugarcane (Rezende et al. 2011), mostly of cellulose (42\%), hemicellulose $(28 \%)$ and lignin $(20 \%)$. These three components amount to more than $90 \%$ of the dry weight of the fiber (Barrera et al. 2016). Sugarcane bagasse can be broken down into simple sugars for producing ethanol (Chandel et al. 2012). In the past, bagasse was considered as an agricultural waste and mostly burnt in boilers to provide the heat and electricity needed for sugar mills. It can also be used to make paper. However, burning of bagasse can cause environment pollution. The most significant pollutant emitted by bagasse-fired boilers is particulate matter (PM). Now, biorefineries have the ability to convert bagasse into bioethanol but not yet commercially used. Model/pilot plants have been built in some sugarcane-growing countries, such as in Thailand, to demonstrate bagassebased ethanol production (http://sugar-asia.com/thail and-successfully-produces-bagasse-based-ethanol-with-enz ymes/). In July, 2018, a Thailand pilot plant was completed for conversion of sugarcane bagasse into raw materials for ethanol (https://www.mitsui.com/jp/en/topics/2018/12265 83_11241.html). According to its website, the factory can process 5,000 tons/year bagasse and produces 1,400 tons of 'cellulosic' sugar, and the sugar will be used for bioethanol and other commercial by-product production. However, due to high lignocellulosic processing cost and technological limitations (such as technologies for conversion of processed bagasse to ethanol), only a handful of commercial companies are currently exploring lignocellulosic

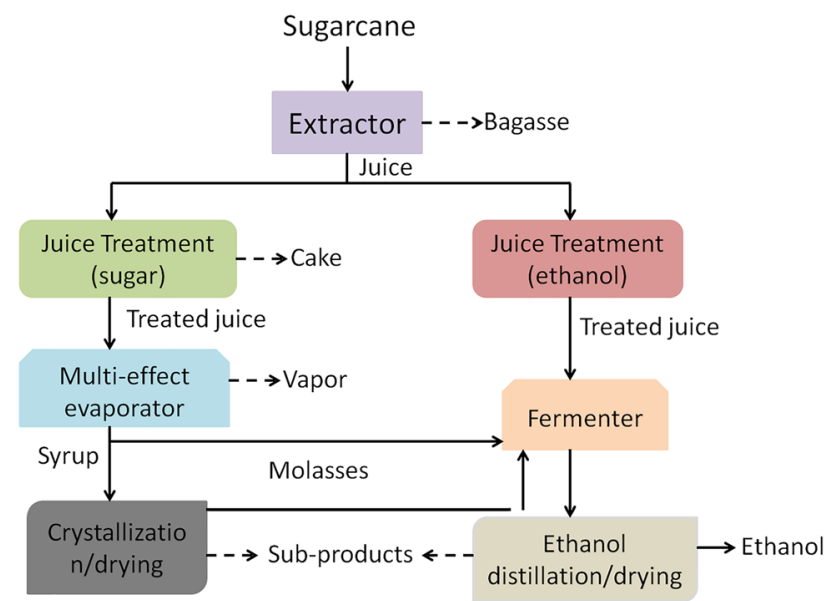

Fig. 1 Schematic representation of different steps of ethanol and sugar production from sugarcane (Figure was reproduced from EGEE 439: Alternative Fuels from Biomass Sources, https://www.e-education.psu.edu/egee439/node/647; with permission from Dr. Caroline Clifford, EMS Energy Institute at Penn State University) biofuel production. Most of these companies use cellulosic materials other than bagasse as feedstock. For example, POET-DSM in the USA produced cellulosic biofuel using corn stover as feedstocks for biofuel production (Yau and Easterling 2018).

The biggest limitation of using lignocellulose for biofuel production is inefficient conversion of lignocellulose into sugars during fermentation. Cellulose and hemicellulose in cell walls can be converted into biofuels. However, a third important cell wall polymer, lignin, has little value for biofuel conversion. Thus, a lignocellulose pre-treatment to separate the tightly bound lignin from cellulose and hemicellulose is a necessary step in lignocellulosic biofuel production. The main purpose of the pre-treatment procedure is to deconstruct the structure of lignocellulosic complexes to facilitate hydrolytic enzymes access cellulose and hemicellulose. There are several pre-treatment strategies. They can be physical, chemical or biological approach. Typical chemical pre-treatments use acids (ex. sulfuric acid $\left(\mathrm{H}_{2} \mathrm{SO}_{4}\right)$ and hydrochloric acid $\left.(\mathrm{HCl})\right)$ or alkalies (ex. sodium hydroxide $(\mathrm{NaOH})$ ) (Bensah and Mensah 2013). Biological approach involves using microorganisms, including bacteria and fungi that biodegrade lignocellulose into sugars for biofuel production. The biological approach is less corrosive, lower by-product formation and relatively inexpensive, compared to chemical and mechanical approaches (Mishra et al. 2018).

Genetic engineering has been successfully used to modify traits in different plant species, using Agrobacterium-mediated and biolistics methods. Thus, transgenesis can be another approach to reduce plant cell wall lignin content for biofuel production. One strategy is to transgenically down-regulate the activity major lignin-biosynthesis genes to reduce bagasse lignin content.

\section{Improving Sugarcane Biomass Traits Through Transgenic Approach}

In addition to conventional breeding, genetic transformation also facilitates the improvement of biomass yield and quality in sugarcane for bioethanol production. Transformation procedures in sugarcane using Agrobacterium, as well as biolistics have been well established and are routinely performed in various institutions and laboratories throughout the world. Recently, Krishnan and Mohan (2017) summarized advances in transformation methods in sugarcane. In addition to the pioneering transgenic technologies, later developments such as RNAi technology and more recently genome editing methods have been used for sugarcane improvement for sugar and bioenergy production (Jung et al. 2012; Jung and Altpeter 2016). 


\section{RNA Interference (RNAi) Technology}

Currently, disruption of cell wall and degradation of lignin requires expensive pre-treatments and high energy processes. Lignin, the second most abundant cell wall heteropolymer, is primarily composed of guaiacyl $(\mathrm{G})$, syringyl (S) and $p$-hydroxyl-phenyl $(\mathrm{H})$ moieties, which in turn are polymerized by sinapyl, $p$-coumaryl and coniferyl alcohols, respectively (Boerjan et al. 2003). Monolignol biosynthesis, a major branch of the phenylpropanoid biosynthesis pathway, consists of ten different enzymes each of which are prospective targets for effective manipulation of lignin content in plants (Bonawitz and Chapple 2010). A diagrammatic representation of the monolignol biosynthetic pathway and the genes involved is depicted in Fig. 2. Down regulation of monolignol biosynthetic genes has resulted in reduced lignin content and altered lignin subunit composition in several bioenergy crops such as alfalfa (Chen and Dixon, 2007), switchgrass (Shen et al. 2012), poplar (Van Acker et al. 2014), maize (Fornale et al. 2012) and sugarcane (Jung et al. 2012, 2013). However, down regulation of lignin biosynthesis genes could result in some negative effects. For example, biomass reduction was observed in down-regulated cinnamoyl-CoA reductase (CCR) poplar plants. CCR catalyzes the first step in the monolignol-specific branch of the lignin (Van Acker et al. 2014). Lignin reduction in major energy crops by biotechnological tools has been extensively reviewed (Sattler et al. 2013; Poovaiah et al. 2014), and the progress made in sugarcane and the biotechnological approaches used are described below.

The RNAi approach has been widely utilized in plants to down-regulate or suppress gene expression with great precision and efficiency. The RNAi mechanism is conserved across eukaryotic organisms and involves doublestranded RNA (dsRNA), Dicer and Argonaute (AGO) family proteins (Baulcombe 2004). Basically, the dsRNA is processed by the Dicer protein into 20-24 nucleotide (nt) small RNA (sRNA) duplex containing 2-nt 3' overhangs at either ends. One sRNA duplex strand binds to the AGO creating an RNA-induced silencing complex (RISC). The sRNA guides the RISC to complementary region of single stranded RNA which is cleaved by the AGO protein at nucleotides corresponding to the central sRNA region of 10-11 nt (Baulcombe 2004).

In sugarcane, the caffeic acid O-methyltransferase (COMT) gene was down-regulated using RNA interference which reduced lignin content up to $13.7 \%$ (Jung et al. 2012). Significant reduction of syringyl/guaiacyl ratio in lignin, compared to wild type plants, was also observed. Through this approach, fermentable glucose yield of up to $29 \%$ from biomass without any pre-treatment process and up to $34 \%$ yield after the dilute acid treatment were achieved. Pre-treatment is a costly and environmentally

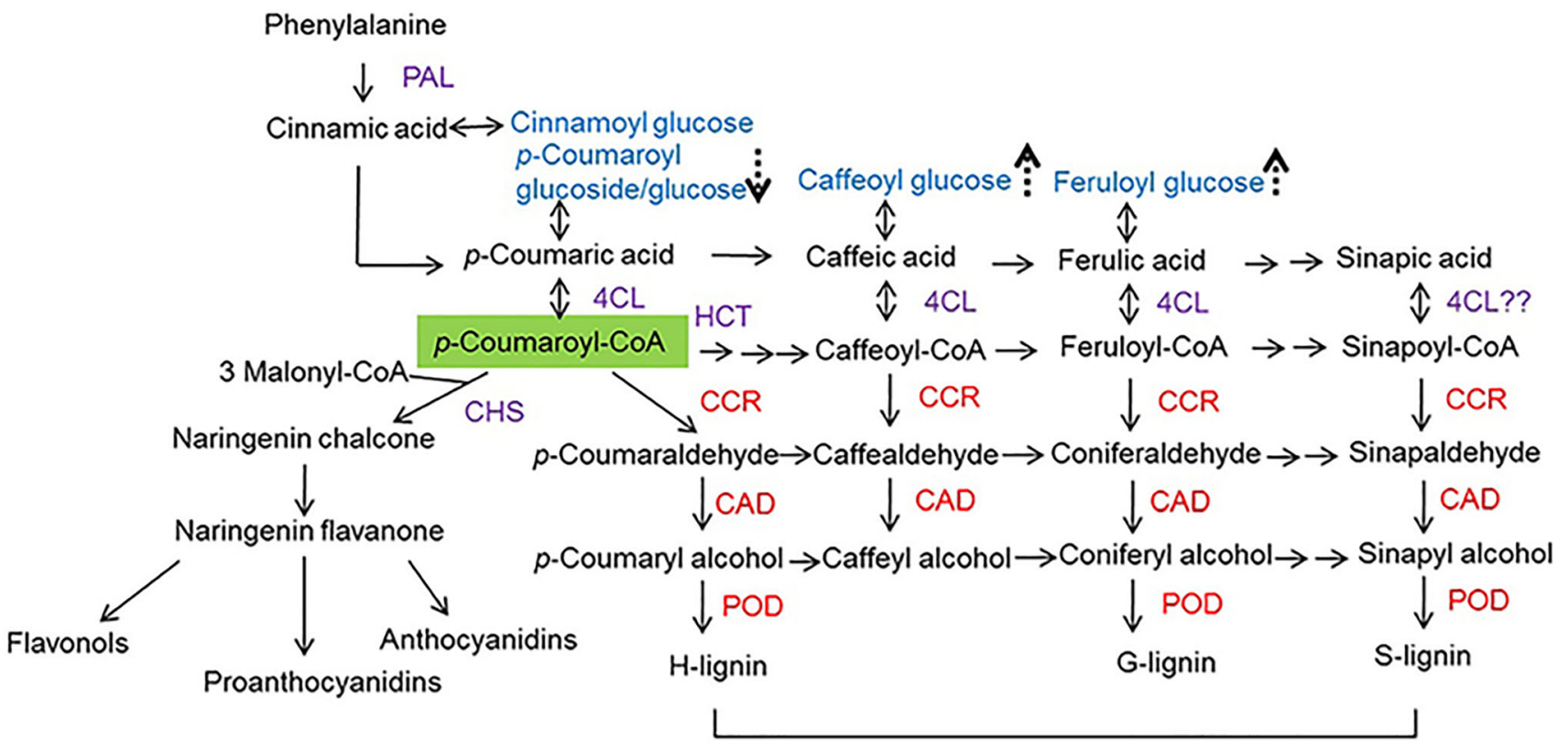

\section{Flavonoid pathway}

Fig. 2 Monolignol biosynthesis pathway in higher plants. CAD, cinnamyl alcohol dehydrogenase; CCR, cinnamoyl-CoA reductase; CHS, chalcone synthase; 4CL, 4-coumaroyl-CoAligase; HCT, hydroxyl cinnamoyl transferase; PAL, phenylalanine ammonia lyase

\section{Monolignol pathway}

and POD, peroxidase (Figure from Yeh et al. 2014, an Open Access article distributed under the terms and conditions of the Creative Commons by Attribution (CC-BY) license, https://creativecommons. org/licenses/by/4.0/]) 
undesirable process in biofuel production. Evaluation of these transgenic lines grown under field conditions showed 80-91\% reduction in COMT transcripts (Jung et al. 2013). The transgenic lines exhibited a reduced total lignin content of $6-12 \%$. Transgenic plants with $6 \%$ reduction in total lignin had no significant difference in biomass yield compared to control plants in a randomized field trial with three replications. Lignin reduction led to enhanced saccharification efficiency, demonstrating that these lines require less hydrolysis compared to wild type plants to obtain fermentable sugars. The same research group used a RNAi approach to down-regulate 4-coumarate: CoA ligase (4CL) gene, and the resultant lines had lignin content reduced by up to $16.5 \%$ without compromising biomass yield. The field-grown RNAi lines also exhibited an increased saccharification efficiency of 52-76\% compared to the wild type control sugarcane plants (Jung et al. 2016).

In another report, RNAi was used to suppress the expression of three important genes related to lignin biosynthesis in sugarcane: caffeoyl-CoA O-methyltransferase (CCOAOMT), ferulate 5-hydroxylase $(F 5 H)$ and $C O M T$, and some of the resultant transgenic lines exhibited enhanced sucrose levels and improved bagasse quality although only one line showed reduced lignin content (Bewg et al. 2016). However, this RNAi line with lowlignin exhibited shorter internodes when compared to the untransformed wild-type sugarcane. Taken together, these results demonstrate that RNAi approach is a promising and successful strategy to alter lignin composition in sugarcane for improving the bioconversion of lignocellulosic biomass into bioethanol.

\section{Gene-editing (GE) Technology}

\section{Gene-editing Tools}

Gene-editing (GE) tools have revolutionized the field of biology, because of their ability to precisely target a particular gene (gene of interest) for modification. Gene editing has offered plant breeders more opportunities to optimize food production. Gene editing can generate a permanent knockout of an allele or insertion in a gene for gain-of-function purpose. The technology is capable of creating knock-out phenotypes in most cases, which is desirable in the majority of potential applications (Boettcher and McManus 2015; Smith et al. 2017).

In the past, various GE systems have been developed for eukaryotic genome manipulation, including those for plants. These systems include meganucleases (Puchta et al. 1993), zinc finger nucleases (ZFNs) (Carroll 2011), transcription activator-like effector nucleases (TALENs) ( $\mathrm{Li}$ et al. 2012) and the most popular Clustered Regularly Interspaced Palindromic Repeat (CRISPR)-associated protein 9 system (CRISPR-Cas9) (Cong et al. 2013). The earlier systems, ZFN and TALEN, involving complex technical designs in order to achieve specific targeting, are laborious and time-consuming (Jagannathan et al. 2018). On the other hand, CRISPR-Cas-based GE offers a lowcost, simple, easy-to-use method with higher efficiency.

The common feature of GE tools is the ability to induce site-specific double-strand breaks (DSBs) in genes-of-interest to obtain mutations or use for other applications (review see Puchta 2017). Double-strand breaks are subsequently repaired through cellular DNA repair mechanisms, i.e. non-homologous end joining (NHEJ) or homology-directed repair (HDR) pathway (Waterworth et al. 2011). Non-homologous end joining is the preferred but often imprecise mechanism of DSB repair in somatic plant cells. Indels (insertions and deletions) are generally generated at the repaired DSB sites when NHEJ-repairing system is used. These indels disrupt the gene and create mutations for the gene. NHEJ is considered to be more efficient than the HDR mechanism for mutant creation (Huang and Puchta 2019). Researchers employ genome editors and the host repair mechanisms (either NHEJ or HDR) for many applications in crop improvement, such as to knock out an unwanted gene or insert a new gene at a specific locus (Zhang et al. 2019).

\section{CRISPR Systems for Genome Editing}

CRISPRs are the hallmark of a bacterial defense system (Wiedenheft et al. 2012), and they have been adapted for gene editing. There are different types of CRISPR-Cas systems. Each type is characterized by distinct architectures of the effector modules that include unique signature proteins (Koonin and Makarova 2019). CRISPR-Cas9 is the first system to be used for eukaryotic genome editing. It is also the most widely used system for genome editing by far. In this chapter, most cases used for discussion are based on CRISPR-Cas9 system. Basically, the CRISPRCas9 system consists of two different components: a single guide RNA (sgRNA) and a Cas9 nuclease. The sgRNA binds to the target sequence and guides Cas9 enzyme to cleave the target sequence. The target sequence is recognized by the sgRNA by detecting the presence of a 3'-NGG motif [also known as the protospacer adjacent motif (PAM)] in the target sequence (Fig. 3. Theoretically, any DNA with sequence complementarity to the first $20 \mathrm{nt}$ of the sgRNA can be a target, but DNA can only be cut when PAM is present at the 3' end of the DNA targets. Motif sequence of PAM varies depending on the origin of bacteria from which the CRISPR system is derived and the Cas protein variants used. The most commonly used CRISPRCas9 system by far is derived from Streptococcus pyogenes (Sp). The PAM sequence for SpCas9 is 5'-NGG. 


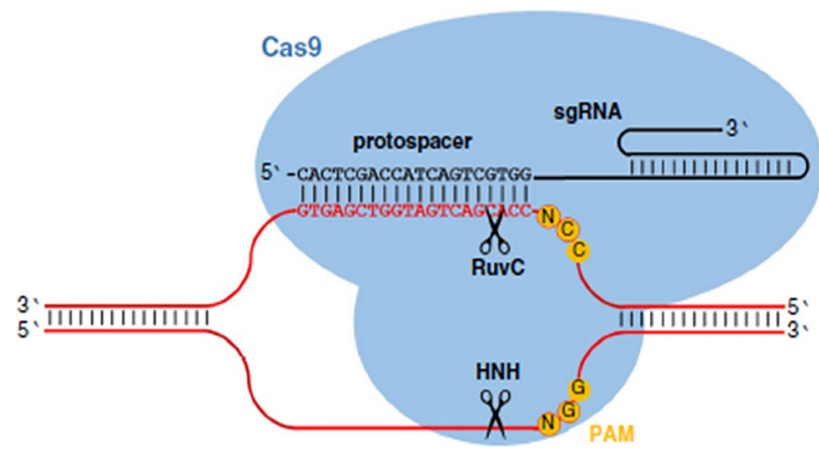

Fig. 3 The CRISPR/Cas9 system of Streptococcus pyogenes (Figure adapted from Puchta 2017, an Open Access article distributed under the terms and conditions of the Creative Commons by Attribution (CC-BY) license, https://creativecommons.org/licenses/by/4.0/])

Sequences of PAM for different bacteria and Cas9 variants can be found at link: https://www.addgene.org/crispr/ guide/\#pam-table. For transcription, the sgRNA is commonly driven by U6 promoters, while the Cas9 gene expression is usually driven by CaMV (cauliflower mosaic virus) $35 \mathrm{~S}$ promoters (for dicots) or ubiquitin promoters (for monocots) (Belhaj et al. 2013). Cas9 gene is usually codon-optimized to the targeted plant-species-of-interest for better expression (Bortesi and Fischer 2015). Nucleus localization signal (NLS) is also frequently fused to the Cas9 gene for more efficiently target Cas9 protein to the nucleus (Belhaj et al. 2013). The CRISPR-Cas9 system has been successfully used for genome editing in many living organisms, including various plant species (Ma et al. 2016). To host a huge amount of CRISPR-Cas-generated plant mutants, researchers from Boyce Thompson Institute in New York have created a platform called Plant Genome Editing Database (PGED; http://plantcrispr.org) to consolidate information about CRISPR/Cas-generated mutants of plant species that have been reported and also being updated (Zheng et al. 2019).

\section{Delivery of CRISPR Components}

CRISPR components may be delivered into the plant genome by DNA, mRNA (in vitro transcripts or IVT) or protein format (review see Ran et al. 2017). With the DNA format, various current plant transformation techniques can be used. The delivery techniques include agroinfiltration (Yin et al. 2015), Agrobacterium infection (Char et al. 2016), biolistics or particle bombardment (Liang et al. 2018), electroporation (Bhowmik et al. 2018), virus-based (Zaidi and Mansoor 2017) and PEG-mediated (protoplastbased) transformation (Malnoy et al. 2016; Lin et al. 2017). Delivery of genome-editing reagents using mRNA format is also efficient and this type of transient delivery results in stable transgenic events and is with reduced off-target effects (Stoddard et al. 2016). Delivery of pre-assembled Cas9-gRNA ribonucleoproteins (RNPs) was also reported. Direct delivery of RNP complex could eliminate the possibility of introducing foreign DNA into the host genome (Wolter and Puchta 2017). Pre-assembled Cas9-gRNA RNPs delivery was first successfully demonstrated in animal cells (Cho et al. 2013). Cas9-gRNA RNPs were then used in plants to successfully deliver into protoplasts (through PEG-mediated) derived from somatic tissues of tobacco, Arabidopsis, lettuce, rice, petunia, grapevine, apple and potato (Woo et al. 2015). Cas9-gRNA RNPs were also successfully delivered into embryo cells by biolistic bombardment in maize (Z. mays L.) and wheat ( $T$. aestivum L.) (Svitashev et al. 2016; Liang et al. 2017, 2018). More recently, a Japanese group directly delivered Cas9-gRNA RNPs into rice zygote cells produced by in vitro fertilization of isolated gametes (Toda et al. 2019). The use of zygote cells for genome editing can effectively reduce the generation of chimera in the later generations (Mao et al. 2019). Lipofection (also known as 'lipid transfection' or 'liposome-based transfection') is frequently used in mammalian DNA transfer (Felgner et al. 1993). More recently, a novel lipofection-mediated transfection approach was used to deliver pre-assembled Cas9gRNA RNP into BY-2 tobacco plant protoplasts for genome editing (Liu et al. 2020). The two lipofection agents used were Lipofectamine 3000 and RNAiMAX. The optimal lipofection efficiencies for Lipofectamine 3000- and RNAiMAX-mediated protein delivery were $66 \%$ and $48 \%$, respectively (Liu et al. 2020).

\section{Editing Efficiency}

CRISPR-Cas9-mediated knock-out efficiency can be significantly affected by factors such as (1) gene location on the chromatin, with editing reported to be more efficient in euchromatin than in heterochromatin (Jensen et al. 2017), (2) sites of sgRNA selection from the gene to be edited (Zhao et al. 2017), (3) number of sgRNA used for a single gene knock-out, (4) sgRNA length (Zhang et al. 2016), (5) Cas9 form for delivery (i.e. as DNA, mRNA or protein) (Kouranova et al. 2016) and (6) Cas9/sgRNA threshold expression level (Yuen et al. 2017). Therefore, to knock out a gene, researchers usually select more than one sgRNA for testing in vitro first and then choose the one with best editing performance and least off-targeting effect for further in vivo work (Liang et al. 2016; Zhao et al. 2017).

\section{Applications of CRISPR Systems}

CRISPR-Cas9 system is widely used to disrupt gene expression by gene knockout. Apart from gene knockouts, 
CRISPR-Cas9 technology can be used to eliminate an entire chromosome (Zuo et al. 2017) or delete an entire gene at a specific locus (Srivastava et al. 2017). Srivastava et al. (2017) have removed a 1.6 Kb GUS gene by using Cas9 and two gRNAs to target each end of the gene. Similarly, it should be able to remove unwanted plant selectable genes (such as kanamycin resistant gene) after transgenesis. Those genes are usually left behind in a transgenic product, and cause great concern for the regulatory agencies and consumers. CRISPR technology can also replace and repair a dysfunctional allele ( $\mathrm{Li}$ et al. $2018 \mathrm{a}, \mathrm{b})$ or generate an opening for integration of a gene at a specific locus (Zhao et al. 2016; Begemann et al. 2017). This site-specific integration by CRISPR technology is unlike the conventional techniques, where random insertion of transgenes occurred. However, CRISPR-Cas9mediated site-directed insertion is much less efficient than CRISPR/Cas9-mediated site-directed deletions. Efforts are underway to increase CRISPR-Cas9-mediated insertion efficiency through different approaches (Rozov et al. 2019). CRISPR technology also has the ability to target multiple loci simultaneously ("multiplexing"). This will be useful for studying members within a gene family. For instance, CRISPR-mediated mutations in a subfamily of abscisic acid receptor genes were shown to promote rice growth and productivity (Miao et al. 2018). In another example, with CRISPR-Cas9, mutations were successfully induced in all four alleles resulting in a complete knockout of the granule bound starch synthase (GBSS) enzyme function in potato $(2 n=4 \mathrm{x})$ (Andersson et al. 2018).

Recently, Liu et al. (2018) generated homozygous mutants in switchgrass, a polyploid bioenergy crop. CRISPR-Cas9-mediated multiplexed gene-editing was also successful in allotetraploid Brassica napus (Yang et al. 2017). Figure 4 shows mutated target sequences after CRISPR-Cas9-mediated gene-editing at multiple loci with a single sgRNA. The mutagenesis was done on BnaRGA family genes, orthologs of Arabidopsis REPRESSOR OF GA1-3 (RGA) gene, which acts as a master repressor in gibberellic signaling. Deletion and insertion of bases at the DSB sites were observed (Fig. 4). Other studies demonstrated that the technology works effectively with certain plant species containing complex and huge genomes such as wheat (Triticum aestivum L.). Recently, CRISPR-Cas9 was used to successfully knock out all 6 alleles of 3 very similar homoeologs of gene TaGW2 in bread wheat (Triticum aestivum L., AABBDD, $2 n=6 x=42$ ), which regulates grain weight control. The mutation has changed the gene from wild genotype $(A A B B D D)$ to mutant genotype (aabbdd) (Liang et al. 2017).

Another important feature of CRISPR technology is that it can be used to regulate gene expression. In this case, Cas9 is engineered into an inactive form, dCas9 (' $\mathrm{d}$ ' stands for dead), and used for specific gene activation (termed CRISPRa, or CRISPR activation) or suppression (termed CRISPRi, or CRISPR interference). Genetic diversity is the key base for crop improvements through plant breeding. Plant breeders rely on diverse crop genetic resources and breeding strategies to incorporate genetic diversity to improve elite cultivars. The CRISPR-Cas system now provides promising new opportunities to create genetic diversity for breeding in an unprecedented way (Wolter et al. 2019). For example, in several publications, CRISPRCas system has been used to edit regulatory regions or elements to generate an array of novel alleles with varying expression level. Meanwhile, researchers at Cold Spring Harbor Laboratory have generated new weak transcriptional alleles in tomato and optimized its inflorescence architecture (Soyk et al. 2017). Advanced imaging systems based on CRISPR/dCas9 were also invented. Dreissig et al. (2017) used fluorescence proteins (eGFP or mRuby2) fused to dCas9 to visualize telomere repeats in tobacco (Nicotiana benthamiana L.) leaf cells. This method traced telomere movement of $2 \mu \mathrm{m}$ over 30 min during interphase (Dreissig et al. 2017). For a review on CRISPRa/CRISPRi and other CRISPR/dCas9 platform-based technologies, see the recent paper by Moradpour and Abdulah (2020).

The other advantage of using GE techniques is that homozygotes with bi-allelic and mono-allelic mutations can be readily achieved in $T_{0}$ generation, reducing the breeding time dramatically (Zhang et al. 2014). For conventional method, it could take a couple of generations of progeny tests to isolate a homozygous transgenic line from a population, especially when multiple homozygous loci are needed. Multiple alleles in a polyploidy crop can also be targeted simultaneously, as mentioned above, and help breeders to speed up plant breeding process and accelerate the rate of crop improvement (Watson et al. 2018).

Recently, scientists have harnessed the unique properties of the Cas12 and Cas13 nucleases to develop nucleic acid diagnostic kits for plant diseases and human diseases (such as COVID-19). One such kit in the USA is the SHERLOCK $^{\mathrm{TM}}$ CRISPR kit, which is developed by the Broad Institute researchers (Abudayyeh et al. 2019). The SHER$\mathrm{LOCK}^{\mathrm{TM}}$ platform with color-based lateral flow readout is easy to use (portable), fast ( $15 \mathrm{~min})$, accurate and quantitative, and no need of a sophisticated machine (fieldready). Due to these distinctive advantages, CRISPR-Cas9 system has become the most preferred transformation technology for eukaryotic genomes/genes.

Limitations of Using CRISPR Systems In spite of many advantages, certain limitations for using CRISPR-Cas9 technique remain (Botella 2019). Limitations include (1) specific PAM sequence requirements that may limit the target sites for Cas9 at certain loci, (2) large-size of Cas9 
Fig. 4 Genotype of BnaA6.RGA-sgRNA CRISPR lines (L4 and L6) in the T0 generation. Bases printed in green indicate the 3'-NGG motif, while the bases in red indicate the 'target sequence' (Figure from Yang et al. 2017, an Open Access article distributed under the terms and conditions of the Creative Commons by Attribution (CCBY) license, https://creativecommons.org/ licenses/by/4.0/])

\section{BnaA6-sgRNA1-L4}

Allele 1: GGTTACAAGGTTAGGTCTTCGGAGATGGCTGACGTTGCGTT

Allele 2: GGTTACAAGGTTAGGTCT-------TGGCTGACGTTGCGTT

Allele 3: GGTTACAAGGTTAGGTC-----AGATGGCTGACGTTGCGTT

Ref: GGTTACAAGGTTAGGTCTTCGGAGATGGCTGACGTTGCGTT

BnaA6-sgRNA2-L4

Allele 1: TTACAACCCCGCTGAGC-----TCGTGGCTTGATAACATGC

Allele 2: TTACAACCCCGCTGAG------TCGTGGCTTGATAACATGC

Allele 3: TTACAACCCCGCTGAGCTTTACTCGTGGCTTGATAACATGC

Ref: TTACAACCCCGCTGAGCTTTACTCGTGGCTTGATAACATGC

Deletion

Deletion

WT

BnaA6-sgRNA1-L6

Allele 1: GGTTACAAGGTTAGGTC-----AGATGGCTGACGTTGCGTT

Allele 2: GGTTACAAGGTTAGG--------ATGGCTGACGTTGCGTT

Ref: GGTTACAAGGTTAGGTCTTCGGAGATGGCTGACGTTGCGTT

Deletion

Deletion

BnaA6-sgRNA2-L6

Allele 1: TTACAACCCC-----------TCGTGGCTTGATAACATG

Allele 2: TTACAACCCCGCTGAGCTTTACCTCGTGGCTTGATAACATG

Deletion

Insertion molecule (difficult for delivery into cells), (3) the mesophilic nature of the established Cas9 system does not allow for applications that require elevated temperatures (Harrington et al. 2017; Mougiakos et al. 2017), (4) less efficient when employing the cellular process of homologydirected DNA repair (HDR) in the technique and (5) offtarget effects (which cause unwanted gene disruption). These disadvantages led to engineer Cas9 variants to expand PAM (Cebrian-Serrano and Davies 2017) and search for novel CRISPR systems. Some of the newly discovered alternatives are CRISPR-Cpf1 (which could increase specificity; Zetsche et al. 2015; Li et al. 2018a, b), CRISPR-CasX and CRISPR-CasY (small Cas proteins for easy delivery; Burstein et al. 2017), CRISPR-GeoCas9 (Harrington et al. 2017) and CRISPR-ThermoCas9 (Mougiakos et al. 2017). GeoCas9 is from thermophilic bacterium Geobacillus stearothermophilus, and it tolerates higher temperature to $70{ }^{\circ} \mathrm{C}$ (active from $20^{\circ} \mathrm{C}-70^{\circ} \mathrm{C}$ ). ThermoCas9 was used for gene deletion and transcriptional silencing at $55{ }^{\circ} \mathrm{C}$ in Bacillus smithii and for gene deletion at $37{ }^{\circ} \mathrm{C}$ in Pseudomonas putida, a tool can be used at broaden temperature range (Mougiakos et al. 2017). For plant genome-editing, CRISPR-Cas9 and CRISPR-Cpf1 (Zaidi et al. 2017) are currently the two most used systems. The other systems listed above are, for now, used for mammalian cell studies. With the added useful features, the new Cas proteins are potential valuable additions for plant genome manipulation. Further, strategies for increasing HR-mediated gene modification frequencies in plants when Cas9-mediated induction of DSBs is used, and elimination of off-target editing are being pursued (Steinert et al. 2016;
Hahn et al. 2018; Huang and Puchta 2019). This includes inhibition of NHEJ to help improving HR-based genemodification frequencies (Endo et al. 2016; NishizawaYokoi et al. 2016). Off-target editing is a major concern with GE technology (Fu et al. 2013; Hahn and Nekrasov 2019). Reduction of off-target editing frequency has become one of the most important tasks in GE technology. Strategies to reduce the incidence and development of techniques/tools to detect off-target editing events are emerging (Fu et al. 2014; Lawrenson et al. 2015; Ran et al. 2015; Zhang et al. 2018a, b). For example, occurrence of off-target mutations in wheat cells is much lower when RNP form was used to deliver CRISPR-Cas9 components, instead of using plasmid (DNA) form. (Liang et al. 2017).

It is worth mentioning that new generations of CRISPRCas genome-editing technologies are emerging. They are used for RNA editing and single-base editing. Except editing DNA, some newly discovered CRISPR-Cas systems can be used to edit mRNA, such as CRISPR/Cas13based systems (Abudayyeh et al. 2016), which include CRISPR-Cas13a (previously known as C2c2) (Abudayyeh et al. 2017), CRISPR-Cas13b (Smargon et al. 2017), CRISPR-Cas13d (Yan et al. 2018) and CRISPR-CasRx (belongs to Cas13d family) (Konermann et al. 2018). RNA editing has multiple advantages over traditional DNAediting. Editing RNA avoids genomic (DNA level) offtargets or indels introduced through non-homologous end joining (NHEJ) (Wolter and Puchta, 2018). Novel protocols have also been developed recently for 'single-base' editing in DNA (Gaudelli et al. 2017) and mRNA (Cox et al. 2017). For DNA single-base editing, two types of 
base conversion can be achieved: $\mathrm{C} \cdot \mathrm{G}$ to $\mathrm{T} \cdot \mathrm{A}$ or $\mathrm{A} \cdot \mathrm{T}$ to G.C. Precise A.T to G.C base editing was first described in rice by Lu and Zhu (2017). In their study, 6 out the 23 lines showed expected $\mathrm{T}$ to $\mathrm{C}$ substitutions at a target region. Hao et al. (2019) used single-base editing to fix the mutant amylose gene $W x-m q$ through A.T to G.C base editing. Current advances, limitations and applications of base-editor in crops have been reviewed recently by Mishra et al. (2020).

\section{Regulation of CRISPR-edited Products}

CRISPR mutant lines can be produced to exclusively harbor the desired mutation for a specific gene without any vector backbones or transgene left (Malnoy et al. 2016; Liang et al. 2017). This type of genome-edited organisms, including crops evades regulation from regulatory agencies in the US (Nature Plants Editorial 2018). In 2016, a genome-edited mushroom (Agaricus bisporus) became the first deregulated plant in USA (Waltz 2016). In April 2018, the US Department of Agriculture (USDA) announced that they have no intention to regulate some categories of genome-edited crops (USDA Press Release, Release No. 0070.18). In the statement, it states 'USDA does not regulate or have any plans to regulate plants that could otherwise have been developed through traditional breeding techniques as long as they are not plant pests or developed using plant pests.' (https://www.usda.gov/ media/press-releases/2018/03/28/secretary-perdue-issuesusda-statement-plant-breeding-innovation). Similarly, in April 10, 2019, OGTR from Australian government also announced not to regulate the use of gene-editing techniques in plants, animals and human cell lines that do not introduce new genetic material (Mallapaty 2019). This is a great relief for many GM crop companies, especially small ones. With regulation, it would take a minimum of six years and require $\$ 30-\$ 50$ million to test and collect the data required for bringing a crop to market (Waltz, 2018). Because of that, more companies are having CRISPR products in their pipelines. For example, Corteva (agricultural division of DowDuPont; USA) has developed waxy hybrid corn from 12 elite inbred lines (Gao et al. 2020). The modification alters starch composition, which is preferable for some cooking and industrial uses. CRISPR-Cas9 system was employed to precisely knock out the Waxyl gene. From 25-location field trials, it showed that CRISPR-waxy hybrids were agronomically superior to introgressed hybrids (Gao et al. 2020). Similarly, Yield10 Bioscience (USA) has developed a high-oil content Camelina sativa using CRISPR-Cas9 system. According to Yield10 Bioscience, in January 2020, USDA-APHIS's Biotechnology Regulatory Services (BRS) has confirmed that 'its genome-edited Camelina sativa plant lines developed using CRISPR-Cas9 for increased oil content are not regulated articles under BRS regulations.' The clarification of the regulatory status of the triple genome-edited Camelina plant lines accelerates the path to conducting field trials in the United States (https://www.globenewswire.com/news-release/2020/04/ 27/2022462/0/en/Yield10-Bioscience-Obtains-PositiveResponse-from-USDA-APHIS-on-Regulatory-Status-of-itsCRISPR-Genome-Edited-C3007-Trait-in-Camelina-Pavingthe-Way-for-U-S-Field-Tests.html). The other company is Pairwise Plants, a start-up company founded in 2018. The company is cooperating with St. Louis-based agribusiness giant Monsanto on gene-editing corn, soybeans, wheat, cotton and canola crops (https://pairwise.com/insights/news/ pairwise-licenses-crispr-technologies-from-massachusettsgeneral-hospital-mgh-and-broad-institute/).

Unfortunately, in Europe, the Court of Justice of European Union has ruled that crops and food created using gene-editing techniques (Case C-528/16) will be subjected to the same regulations as those governing genetically modified organisms (Callaway 2018). In summary, regulation for USA is a product-triggered system, while in Europe it is a process-triggered system (where as long as DNA manipulation is used, the outcome brings uncertainties and higher risk). As pointed out by Schiemann et al. (2020), these still ongoing decision-making processes, however, are heading in very different directions, resulting in complex geographical patterns of different regulations. Although the regulatory agencies do not regulate some genome-editing products, the acceptance of this new breeding technique by customers is also important for successfully developing these products. According to a recent survey, the lay public tended to consider gene editing as closer to older genetic modification. However, they showed a dramatic increase in supporting the new technology after being provided information (Kato-Nitta et al. 2019). So, educating the public is an important part of public acceptance of GE technology.

\section{Current Status of Genome Editing in Sugarcane}

The first genome editing of sugarcane was reported by Jung and Altpeter (2016). They used TALENs to knockout COMT gene in sugarcane for reducing lignin content. They achieved target mutations in $74 \%$ of transgenic lines created and observed that $8-99 \%$ of the wild-type COMT alleles could be mutated in various lines. The transgenic events that exhibited $99 \%$ mutation frequency presented a $29-32 \%$ reduction of lignin content compared to the control untransformed plants in glasshouse trials. Moreover, the mutations and the mutant phenotypes did not change in the vegetatively multiplied clones. Although it is unclear 
why 99\% mutation frequency only caused 29-32\% reduction of lignin content in that transgenic plants, it has been suggested that 'biological plasticity' can rescue target activity of knockouts in some cases. For instance, Smits et al. (2019) reported that they have observed residual protein expression for about one-third of the quantified targets, at varying degrees from low to original level from 136 distinct genes generated by CRISPR-induced frameshifts in HAP1 cells.

The genome-edited lines were assessed for their mutation efficiency and agronomic performance in field conditions (Kannan et al. 2018). The mutant lines exhibited decrease in 'syringyl to guaiacyl' ratio and reduction of lignin content up to $19.7 \%$. These lines demonstrated enhanced saccharification efficiency (up to $43.8 \%$ ) without compromising the biomass production when compared to control plants. Interestingly, sequences of the COMT region in one mutant line CB6 revealed that 107 COMT alleles were edited out of a total 109 copies. CB6 showed reduced lignin content of $19 \%$ with improved saccharification efficiency of 54\% and its agronomic traits resembled that of control plant. These findings suggested that GE tools can be effectively used for sugarcane genome modification.

Manipulation of complex genomes necessitates high specificity in targeting without any or very low off-target effects in order to avoid unnecessary mutations and cell toxicity. In addition, an ideal genome engineering system is one which can be easy to design, with precise targeting and efficient delivery to cells. Although TALENs are easier to generate than ZFNs, they lead to off-target binding (Mahfouz and Li 2011). TALEN-mediated genome-editing requires two distinct TALE nuclease genes in order to form a functional heterodimer around the target, which may hinder efficiency (Gaj et al. 2013). On the contrary, CRISPR-Cas9 system is simpler than the other GE tools for design and implementation. It requires only a simple nuclease and a single gRNA, which are easy to construct and deliver to host cells. It has been proven that certain recalcitrant gene targets to TALENs could be efficiently modified using CRISPR-Cas9 system (Cong et al. 2013; Ran et al. 2013). As a result, CRISPR-Cas9 technology looks to be an important tool for sugarcane gene editing in the future.

Recently, Altpeter and his colleagues have succeeded in editing the sugarcane genome using CRISPR-Cas9 systems (Eid et al. 2021; Oz et al. 2021). Multiple alleles of magnesium chelatase gene were efficiently edited in sugarcane using CRISPR-Cas9 (Eid et al. 2021). In another study, Oz et al. (2021) reported efficient and reproducible gene targeting in sugarcane, enabling precise co-editing of multiple alleles of acetolactate synthase (ALS) gene conferring herbicide resistance via template-mediated and homology- directed repair (HDR) of DNA double-strand breaks induced by CRISPR/Cas9. These reports imply that CRISPR-Cas9 can be effectively used to target complex polyploids like sugarcane and have broadened the scope for sugarcane genome editing.

\section{Prospects and Challenges of Genome Editing in Sugarcane}

Typically, developing sugarcane varieties by conventional breeding is laborious and time consuming. A breeding cycle, from crossing-to-release, usually takes $12-15$ years (Gazaffi et al. 2010). Additionally, manipulation of multiple genes or complex metabolic pathways by conventional breeding is almost impossible. Application of GE techniques, especially the CRISPR-Cas9 system, in a complex polyploid plant species, such as sugarcane, for genome modification has several advantages. CRISPR-Cas9-based genome-editing can generate precise mutations on both single and multiple genes accurately and more rapidly than other systems. Although CRISPR-Cas9 system has been widely applied to different plant species (Ma et al. 2016), there are few reports of CRISPR-Cas9-mediated geneediting in sugarcane as we write this paper. This is partially due to the lack of information of sugarcane genome sequence information in the past. The complex genome (Manners et al. 2004) and high polyploidy of sugarcane (Premachandran et al. 2011) has hindered genome sequencing and functional genomics studies to a great extent in this crop (Mohan, 2016). Genome-editing requires prior knowledge about the genome sequence information in order to design specific sgRNAs for gene targeting. If a gene associated with a particular trait is known and its DNA sequence is available, CRISPR-Cas9 can be used to directly target the gene to modify the trait.

CRISPR technology can also be used to identify genes associated with a specific trait. For example, Huang et al. (2018) identified a large number of rice high-yield genes by pedigree analysis, whole-genome sequencing and CRISPRCas9 gene knockout. They first identified 28 ancestral chromosomal blocks that were maintained in all the highyield rice cultivars. Then, they randomly selected 57 genes from the 123 loci from the blocks for knockout (or knockdown) studies. Results indicate that a high proportion of these genes are essential or show phenotypic effects related to rice production (Huang et al. 2018). CRISPRCas-based functional genomics screening is also a powerful approach for systematically analyzing and identifying genes associated with particular phenotypes. Meng et al. (2017) generated a CRISPR library containing 25,265 pooled sgRNAs to target 12,786 genes. The sgRNAs were then cloned to form a plasmid library for rice 
transformation. It resulted in more than 14,000 independent $\mathrm{T}_{0}$ lines displaying a high frequency of edits. Among the 200 lines tested, 54 had altered morphological phenotypes.

Lack of genome sequence data was the major obstacle for the use of GE tools for sugarcane genome-editing in the past years. Recently, an early draft of the whole genome from sugarcane hybrid cultivar SP80-3280, a popular commercial variety in Brazil, was released using Illumina TruSeq ${ }^{\circledR}$ Long Read Sequencing technology (RiañoPachón and Mattiello 2017). More recently, Garsmeur et al. (2018) published a monoploid reference genome of sugarcane. In the same year, Zhang et al. sequenced a haploid S. spontaneum AP85-441 resulting in an allele defined genome (Zhang et al. 2018a, b). The availability of recent drafts of sugarcane genome information will open more opportunities for researchers to utilize CRISPR-Cas systems for precise targeting in sugarcane (Zhang et al. 2018a, b; Souza et al. 2019). However, having a reference genome might not be enough. A high-quality sequence information is still needed. Even a 1-bp difference between the real and the reference genome can prevent genome editing. Besides, the sequence of the genotype to be edited can be different from the reference one. Thus, it is prudent to get target sequences from a given genotype before starting to edit.

Another significant limitation of GE in sugarcane is the time-consuming transformation procedures. Although several successful reports of sugarcane transformation are available (Augustine et al. 2015a, b, c a, b and c) the transformation efficiency in sugarcane is lower when compared to other crops (Joyce et al. 2010). Therefore, developing an efficient sugarcane transformation system for delivering GE components is important (Altpeter et al. 2016). Moreover, transient-assay techniques such as agroinfiltration and use of protoplasts, which are popularly used in genome-editing for other plant species, are not readily amenable in sugarcane (Mohan 2016). Recently, Lowe et al. (2016) showed that overexpressing the maize (Zea mays) developmental genes Baby Boom (Bbm) and Wuschel2 (Wus2) could improve the transformation efficiency of monocots. They have demonstrated using this approach to increase transformation efficiency in sorghum (Sorghum bicolor) immature embryos, sugarcane (Saccharum officinarum) callus, indica rice (Oryza sativa ssp indica) callus, and to induce high transformation frequencies in previously non-transformable maize inbred lines (Lowe et al. 2016). Owing to phenotypic abnormalities and sterility in transgenic plants of using constitutive promoter, they recently employed a tissue-specific promoter, ZmPLTP (phospholipid transferase protein) promoter, to alleviate this issue and generate fertile transgenic lines
(Lowe et al. 2018). The method can generate abundant transformed embryos which can directly germinate into plants without going through callus status. Use of such morphogenic regulators instead of hormones would thus enhance transformation efficiency of monocot species particularly sugarcane and energy cane (Lowe et al. 2018).

\section{Conclusion and Future Perspectives}

The growing human population and limited agricultural lands necessitate continued crop improvement for food security. Increasing crop yields through conventional plant breeding is successful but incremental and relatively slow. It can take several years to breed new varieties. Biotechnological techniques offer more opportunities to accelerate crop improvement (Watson et al. 2018). Genome editing tools, especially CRISPR-Cas9 system, are useful in this regard. The technology can precisely target gene-of-interest for modification, and can reduce the time needed to produce a variety. Conventional transgenic techniques, although successful in producing commercialized crops with enhanced traits, remain controversial. This has created a negative impact on transgenic crops. In this context, the emergence of CRISPR-Cas9-based genome editing system may become a more acceptable option. US Department of Agriculture (USDA) and Australian OGTR issued statements, indicating that they do not intend to regulate crops produced from New Breeding Techniques (NBT), such as CRISPR-Cas9, and consider them indistinguishable from those developed through traditional breeding methods. These are positive developments for biotech companies, breeders and researchers using CRISPR to modify plants.

CRISPR-Cas9 has been employed to improve the quantity and quality of several biofuel feedstocks, such as algae (Ajjawi et al. 2017) and plant cell walls (Zhou et al. 2015; Park et al. 2017). It was also used to engineer fermentation yeasts for more efficient bioethanol production (Lee et al. 2017). Sugarcane is one of the major biofuel feedstocks. Its juice is used for first-generation biofuel production, and its fiber is a potential feedstock for secondgeneration biofuel production. Considerable investment has been made to improve sugarcane quality and quantity by transgenesis with very limited commercial outcomes (Kandel et al. 2018). We believe that sugarcane genome editing will be used to elucidate the function of important genes and their potential application in sugarcane, including for bioenergy production.

Acknowledgements CM is grateful to the São Paulo Research Foundation (FAPESP, Proc. 2015/10855-9 and Proc. 2018/11544-5) for the postdoctoral and visiting research fellowships. 


\section{Declarations}

Conflict of interest The authors state that they have no conflicts of interest.

\section{References}

Abudayyeh, O.O., J.S. Gootenberg, S. Konermann, J. Joung, I.M. Slaymaker, D.B. Cox, S. Shmakov, K.S. Makarova, E. Semenova, L. Minakhin, K. Severinov, A. Regev, E.S. Lander, E.V. Koonin, and F. Zhang. 2016. C2c2 is a single-component programmable RNA-guided RNA-targeting CRISPR effector. Science 353: aaf5573.

Abudayyeh, O.O., J.S. Gootenberg, P. Essletzbichler, S. Han, J. Joung, J.J. Belanto, V. Verdine, D.B.T. Cox, M.J. Kellner, A. Regev, E.S. Lander, D.F. Voytas, A.Y. Ting, and F. Zhang. 2017. RNA targeting with CRISPR-Cas13. Nature 550: $280-284$

Abudayyeh, O.O., J.S. Gootenberg, M.J. Kellner, and F. Zhang. 2019. Nucleic acid detection of plant genes using CRISPR-Cas13. CRISPR Journal 2 (3): 165-171.

Aitken, K.S., P.A. Jackson, and C.L. McIntyre. 2005. A combination of AFLP and SSR markers provides extensive map coverage and identification of homo(eo)logous linkage groups in a sugarcane cultivar. Theoretical and Applied Genetics 110: 789-801.

Ajjawi, I., J. Verruto, M. Aqui, L.B. Soriaga, J. Coppersmith, K. Kwok, L. Peach, E. Orchard, R. Kalb, W. Xu, T.J. Carlson, K. Francis, K. Konigsfeld, J. Bartalis, A. Schultz, W. Lambert, A.S. Schwartz, R. Brown, and E.R. Moellering. 2017. Lipid production in Nannochloropsis gaditana is doubled by decreasing expression of a single transcriptional regulator. Nature Biotechnology 30: 647-652.

Altpeter, F., N. Baisakh, R. Beachy, R. Bock, T. Capell, P. Christou, H. Daniell, K. Datta, S. Datta, P.J. Dix, C. Fauquet, N. Huang, A. Kohli, H. Mooibroek, L. Nicholson, T.T. Nguyen, G. Nugent, K. Raemakers, A. Romano, D.A. Somers, E. Stoger, N. Taylor, and R. Visser. 2005. Particle bombardment and the genetic enhancement of crops: Myths and realities. Molecular Breeding 15: 305-327.

Altpeter, F., N.M. Springer, L.E. Bartley, A.E. Blechl, T.P. Brutnell, V. Citovsky, L.J. Conrad, S.B. Gelvin, D.P. Jackson, A.P. Kausch, P.G. Lemaux, J.I. Medford, M.L. Orozco-Cárdenas, D.M. Tricoli, J. Van Eck, D.F. Voytas, V. Walbot, K. Wang, Z.J. Zhang, and C.N. Stewart. 2016. Advancing crop transformation in the era of genome editing. The Plant Cell 28: 1510-1520.

Amalraj, V.A., and N. Balasundaram. 2006. On the taxonomy of the members of 'Saccharum complex.' Genetic Resources and Crop Evolution 53: 35-41.

Andersson, M., H. Turesson, N. Olsson, A.S. Fält, P. Ohlsson, M.N. Gonzalez, M. Samuelsson, and P. Hofvander. 2018. Genome editing in potato via CRISPR-Cas9 ribonucleoprotein delivery. Physiologia Plantarum 164 (4): 378-384.

Araújo, K., D. Mahajan, R. Kerr, and M. da Silva. 2017. Global biofuels at the crossroads: An overview of technical, policy, and investment complexities in the sustainability of biofuel development. Agriculture 7 (4): 32.

Augustine, S.M., J.A. Narayan, D.P. Syamaladevi, C. Appunu, M. Chakravarthi, V. Ravichandran, et al. 2015a. Erianthus arundinaceus HSP70 (EaHSP70) overexpression increases drought and salinity tolerance in sugarcane (Saccharum spp. hybrid). Plant Science 232: 23-34.

Augustine, S.M., J.A. Narayan, D.P. Syamaladevi, C. Appunu, M. Chakravarthi, V. Ravichandran, et al. 2015b. Introduction of Pea DNA Helicase 45 into Sugarcane (Saccharum spp. Hybrid) enhances cell membrane thermostability and upregulation of stress-responsive genes leads to abiotic stress tolerance. Molecular Biotechnology 57: 475-488.

Augustine, S.M., J.A. Narayan, D.P. Syamaladevi, C. Appunu, M. Chakravarthi, V. Ravichandran, et al. 2015c. Overexpression of EaDREB2 and pyramiding of EaDREB2 with the pea DNA helicase gene (PDH45) enhance drought and salinity tolerance in sugarcane (Saccharum spp. hybrid). Plant Cell Reports 34: 247-263.

Balat, M., H. Balat, and C. Öz. 2008. Progress in bioethanol processing. Progress in Energy and Combustion Science 34: 551-573.

Barrera, I., M.A. Amezcua-Allieri, L. Estupiñan, T. Martínez, and J. Aburto. 2016. Technical and economical evaluation of bioethanol production from lignocellulosic residues in Mexico: Case of sugarcane and blue agave bagasses. Chemical Engineering Research and Design. 107: 91-101.

Baulcombe, D. 2004. RNA silencing in plants. Nature 431: 356-363. Begemann, M.B., B.N. Gray, E. January, G.C. Gordon, Y. He, H. Liu, X. Wu, T.P. Brutnell, T.C. Mockler, and M. Oufattole. 2017. Precise insertion and guided editing of higher plant genomes using Cpf1 CRISPR nucleases. Scientific Reports 7 (1): 11606.

Belhaj, K., A. Chaparro-Garcia, S. Kamoun, and V. Nekrasov. 2013. Plant genome editing made easy: Targeted mutagenesis in model and crop plants using the CRISPR/Cas system. Plant Methods 9: 39.

Bensah, E.C., and M. Mensah. 2013. Chemical pretreatment methods for the production of cellulosic ethanol: technologies and innovations. International Journal of Chemical Engineering (hindwi). 2013: 719607.

Bertrand, E., L.P.S. Vandenberghe, C.R. Soccol, J.C. Sigoillot, and C. Faulds. 2016. First generation bioethanol In. Green fuels technology: Springer International Publishing, Switzerland.

Bewg, W.P., C. Poovaiah, W. Lan, J. Ralph, and H.D. Coleman. 2016. RNAi downregulation of three key lignin genes in sugarcane improves glucose release without reduction in sugar production. Biotechnology for Biofuels 9: 270.

Bhowmik, P., E. Ellison, B. Polley, V. Bollina, M. Kulkarni, K. Ghanbarnia, H. Song, C. Gao, D.F. Voytas, and S. Kagale. 2018. Targeted mutagenesis in wheat microspores using CRISPR/ Cas9. Scientific Reports 8: 6502.

Bilal, M., M. Saeed, I.A. Nasir, B. Tabassum, M. Zameer, A. Khan, M. Tariq, A.J. Mohamed, and T. Husnain. 2015. Association mapping of cane weight and tillers per plant in sugarcane. Biotechnology and Biotechnological Equipment 29: 617-623.

Boerjan, W., J. Ralph, and M. Baucher. 2003. Lignin biosynthesis. Annual Review of Plant Biology 54: 519-546.

Boettcher, M., and M.T. McManus. 2015. Choosing the right tool for the job: RNAi, TALEN or CRISPR. Molecular Cell 58 (4): 575-585.

Bonawitz, N.D., and C. Chapple. 2010. The genetics of lignin biosynthesis: Connecting genotype to phenotype. Annual Review of Genetics 44: 337-363.

Bortesi, L., and R. Fischer. 2015. The CRISPR/Cas9 system for plant genome editing and beyond. Biotechnology Advances 33: 41-52.

Botella, J.R. 2019. Now for the hard ones: Is there a limit on CRISPR genome editing in crops? Journal of Experimental Botany 70 (3): 734-737.

Burstein, D., L.B. Harrington, S.C. Strutt, A.J. Probst, K. Anantharaman, and B.C. Thomas. 2017. New CRISPR-Cas systems from uncultivated microbes. Nature 542: 237-241.

Callaway, E. 2018. CRISPR plants now subject to tough GM laws in European Union. Nature 560: 16.

Carrasco-Valenzuela, T., C. Muñoz-Espinoza, A. Riveros, R. Pedreschi, P. Arús, R. Campos-Vargas, and C. Meneses. 2019. Expression QTL (eQTLs) analyses reveal candidate genes 
associated with fruit flesh softening rate in Peach [Prunus persica (L.) Batsch]. Frontiers in Plant Science 10: 1581.

Carroll, D. 2011. Genome engineering with zinc-finger nucleases. Genetics 188: 773-782.

Carvalho-Netto, O.V., J.A. Bressiani, H.L. Soriano, C.S. Fiori, J.M. Santos, G. Barbosa, M.A. Xavier, G.A.L. Landell, and G.A.G. Pereira. 2014. The potential of the energy cane as the main biomass crop for the cellulosic industry. Chemical and Biological Technologies in Agriculture 1: 20.

Cebrian-Serrano, A., and B. Davies. 2017. CRISPR-Cas orthologues and variants: Optimizing the repertoire, specificity and delivery of genome engineering tools. Mammalian Genome 28: 247-261.

Chandel, A.K., S.S. da Silva, W. Carvalho, and O.V. Singh. 2012. Sugarcane bagasse and leaves: Foreseeable biomass of biofuel and bio-products. Journal of Chemical Technology and Biotechnology 87: 11-20.

Char, S.N., A.K. Neelakandan, H. Nahampun, B. Frame, M. Main, M.H. Spalding, P.W. Becraft, B.C. Meyers, V. Walbot, K. Wang, and B. Yang. 2017. An Agrobacterium-delivered CRISPR/Cas9 system for high-frequency targeted mutagenesis in maize. Plant Biotechnology Journal 15 (2): 257-268.

Chen, F., and R.A. Dixon. 2007. Lignin modification improves fermentable sugar yields for biofuel production. Nature Biotechnology 25: 759-761.

Cho, S.W., J. Lee, D. Carroll, J.S. Kim, and J. Lee. 2013. Heritable gene knockout in Caenorhabditis elegans by direct injection of Cas9-sgRNA ribonucleoproteins. Genetics 195 (3): $1177-1180$.

Cong, L., F.A. Ran, D. Cox, S. Lin, R. Barretto, N. Habib, P.D. Hsu, X. Wu, W. Jiang, L.A. Marraffini, and F. Zhang. 2013. Multiplex genome engineering using CRISPR/Cas systems. Science 339: 819-823.

Cox, D.B.T., J.S. Gootenberg, O.O. Abudayyeh, B. Franklin, M.J. Kellner, J. Joung, and F. Zhang. 2017. RNA editing with CRISPR-Cas13. Science 358: 1019-1027.

Dreissig, S., S. Schiml, P. Schindele, O. Weiss, T. Rutten, V. Schubert, E. Gladilin, M.F. Mette, H. Puchta, and A. Houben. 2017. Live cell CRISPR-imaging in plants reveals dynamic telomere movements. Plant Journal 91: 565-573.

Eid, A., C. Mohan, S. Sanchez, D. Wang, and F. Altpeter. 2021. Multiallelic, targeted mutagenesis of magnesium chelatase with CRISPR/Cas9 provides a rapidly scorable phenotype in highly polyploid sugarcane. Frontiers in Genome Editing 3: 654996. https://doi.org/10.3389/fgeed.2021.65499.

Endo, M., M. Mikami, and S. Toki. 2016. Biallelic gene targeting in rice. Plant Physiology 170 (2): 667-677.

FAOSTAT. 2016. Available at http://www.fao.org/faostat/ en/\#data/QC

Fargioni, J., J. Hill, S. Plosky, and P. Hawthorne. 2008. Land clearing and biofuel carbon debt. Science 319: 1236-1238.

Felgner, J., M. Martin, Y. Tsai, et al. 1993. Cationic lipid-mediated transfection in mammalian cells: "Lipofection." Journal of Tissue Culture Methods 15: 63-68.

Fornalé, S., M. Capellades, A. Encina, K. Wang, S. Irar, C. Lapierre, K. Ruel, J.P. Joseleau, J. Berenguer, P. Puigdomenech, J. Rigau, and D. Caparros-Ruiz. 2012. Altered lignin biosynthesis improves cellulosic bioethanol production in transgenic maize plants down-regulated for cinnamyl alcohol dehydrogenase. Molecular Plant 5: 817-830.

Fu, Y., J.A. Foden, C. Khayter, M.L. Maeder, D. Reyon, J.K. Joung, and J.D. Sander. 2013. High-frequency off-target mutagenesis induced by CRISPR-Cas nucleases in human cells. Nature Biotechnology 31: 822-826.

Fu, Y., J.D. Sander, D. Reyon, V.M. Cascio, and J.K. Joung. 2014. Improving CRISPR-Cas nuclease specificity using truncated guide RNAs. Nature Biotechnology 32: 279-284.
Gaj, T., C.A. Gersbach, and C.F.I.I.I. Barbas. 2013. ZFN, TALEN, and CRISPR/Cas-based methods for genome engineering. Trends in Biotechnology 31: 397-405.

Gao, H., M.J. Gadlage, H.R. Lafitte, B. Lenderts, M. Yang, M. Schroder, J. Farrell, K. Snopek, D. Peterson, et al. 2020. Superior field performance of waxy corn engineered using CRISPR-Cas9. Nature Biotechnology 38 (5): 579-581.

Gao, C., and K.K. Nielsen. 2013. Comparison between Agrobacterium-mediated and direct gene transfer using the gene gun. In Biolistic DNA delivery. Methods in molecular biology (Methods and Protocols). Totowa: Humana Press

Garsmeur, O., G. Droc, R. Antonise, J. Grimwood, B. Potier, K. Aitken, J. Jenkins, G. Martin, C. Charron, C. Hervouet, L. Costet, N. Yahiaoui, A. Healey, D. Sims, Y. Cherukuri, A. Sreedasyam, A. Kilian, A. Chan, M.A. Van Sluys, K. Swaminathan, C. Town, H. Bergès, B. Simmons, J.C. Glaszmann, E. van der Vossen, R. Henry, J. Schmutz, and A. D'Hont. 2018. A mosaic monoploid reference sequence for the highly complex genome of sugarcane. Nature Communications 9: 2638.

Gaudelli, N.M., A.C. Komor, H.A. Rees, M.S. Packer, A.H. Badran, D.I. Bryson, and D.R. Liu. 2017. Programmable base editing of A.T to G.C in genomic DNA without DNA cleavage. Nature 551: 464-471.

Gazaffi, R., K.M. Oliveira, A.P. Souza, and A.A.F. Garia. 2010. The importance of the germplasm in developing agro-energetic profile sugarcane cultivars. In Sugar Cane Bioethanol: $R \& D$ for productivity and sustainability, ed. L.A.B. Cortez, pp. 333-343 Sao Paulo: Blucher

Hahn, F., and V. Nekrasov. 2019. CRISPR/Cas precision: Do we need to worry about off-targeting in plants? Plant Cell Reports 38: 437-441.

Hahn, F., M. Eisenhut, O. Mantegazza, and A.P.M. Weber. 2018. Homologydirected repair of a defective glabrous gene in Arabidopsis with Cas9-based gene targeting. Frontiers in Plant Science 9: 424.

Hao, L., Q. Ruiying, L. Xiaoshuang, L. Shengxiang, X. Rongfang, Y. Jianbo, and W. Pengcheng. 2019. CRISPR/Cas9-mediated adenine base editing in rice genome. Rice Science 26: 125-128.

Harrington, L.B., D. Paez-Espino, B.T. Staahl, J.S. Chen, E. Ma, N.C. Kyrpides, and J.A. Doudna. 2017. A thermostable Cas9 with increased lifetime in human plasma. Nature Communications 8: 1424.

Heaton, E.A., F.G. Dohleman, and S.P. Long. 2008. Meeting US biofuel goals with less land: The potential of Miscanthus. Global Change Biology 14: 2000-2014.

Henry, R.J. 2010. Evaluation of plant biomass resources available for replacement of fossil oil. Plant Biotechnology Journal 8: 288-293.

Hoang, N.V., A. Furtado, P.J. Mason, A. Marquardt, L. Kasirajan, P.P. Thirugnanasambandam, F.C. Botha, and R.J. Henry. 2017. A survey of the complex transcriptome from the highly polyploid sugarcane genome using full-length isoform sequencing and de novo assembly from short read sequencing. BMC Genomics 18: 395.

Hoarau, J.Y., L. Grivet, B. Offmann, L.M. Raboin, J.P. Diorflar, J. Payet, M. Hellmann, A. D’Hont, and J.C. Glaszmann. 2002. Genetic dissection of a modern sugarcane cultivar (Saccharum spp.) II. Detection of QTLs for yield components. Theoretical and Applied Genetics 105: 1027-1037.

Huang, T.K., and H. Puchta. 2019. CRISPR/Cas-mediated gene targeting in plants: Finally a turn for the better for homologous recombination. Plant Cell Reports 38: 443-453.

Huang, J., J. Li, J. Zhou, L. Wang, S. Yang, L.D. Hurst, W.H. Li, and D. Tian. 2018. Identifying a large number of high-yield genes in rice by pedigree analysis, whole-genome sequencing, and 
CRISPR-Cas9 gene knockout. Proceedings of the National Academy of Sciences of the USA 115 (32): E7559-E7567.

Inman-Bamber, N.G., and D.M. Smith. 2005. Water relations in sugarcane and response to water deficits. Field Crops Research 92: 185-202.

Inman-Bamber, G. 2013. Sugarcane yields and yield-limiting processes. In Sugarcane: Physiology, biochemistry, and functional biology Eds. Paul H. Moore, Frederik C. Botha, pp 579-600

Jaganathan, D., K. Ramasamy, G. Sellamuthu, S. Jayabalan, and G. Venkataraman. 2018. CRISPR for crop improvement: An update review. Frontiers in Plant Science 9: 985.

Jensen, K.T., L. Fløe, T.S. Petersen, J. Huang, F. Xu, L. Bolund, Y. Luo, and L. Lin. 2017. Chromatin accessibility and guide sequence secondary structure affect CRISPR-Cas9 gene editing efficiency. FEBS Letters 591 (13): 1892-1901.

Jeswani, H.K., A. Chilvers, and A. Azapagic. 2020. Environmental sustainability of biofuels: A review. Proceedings of the Royal Society a: Mathematical, Physical, and Engineering Sciences 476: 20200351.

Joyce, P., M. Kuwahata, N. Turner, and P. Lakshmanan. 2010. Selection system and co-cultivation medium are important determinants of Agrobacterium-mediated transformation of sugarcane. Plant Cell Reports 29: 173-183.

Jung, J.H., and F. Altpeter. 2016. TALEN mediated targeted mutagenesis of the caffeic acid O-methyltransferase in highly polyploid sugarcane improves cell wall composition for production of bioethanol. Plant Molecular Biology 92: 131-142.

Jung, J.H., W.M. Fouad, W. Vermerris, M. Gallo, and F. Altpeter. 2012. RNAi suppression of lignin biosynthesis in sugarcane reduces recalcitrance for biofuel production from lignocellulosic biomass. Plant Biotechnology Journal 10: 1067-1076.

Jung, J.H., W. Vermerris, M. Gallo, J.R. Fedenko, J.E. Erickson, and F. Altpeter. 2013. RNA interference suppression of lignin biosynthesis increases fermentable sugar yields for biofuel production from field-grown sugarcane. Plant Biotechnology Journal 11: 709-716.

Jung, J.H., B. Kannan, H. Dermawan, G.W. Moxley, and F. Altpeter. 2016. Precision breeding for RNAi suppression of a major 4-coumarate:Coenzyme A ligase gene improves cell wall saccharification from field grown sugarcane. Plant Molecular Biology 92 (4-5): 505-517.

Kalunke, R.M., A.M. Kolge, K.H. Babu, and D.T. Prasad. 2009. Agrobacterium-mediated transformation of sugarcane for borer resistance using Cry $1 \mathrm{Aa} 3$ gene and one-step regeneration of transgenic plants. Sugar Technology 11 (4): 355-359.

Kandel, R., X. Yang, J. Song, and J. Wang. 2018. Potentials, challenges, and genetic and genomic resources for sugarcane biomass improvement. Frontiers in Plant Science 9: 151.

Kannan, B., J.H. Jung, G.W. Moxley, S.M. Lee, and F. Altpeter. 2018. TALEN-mediated targeted mutagenesis of more than 100 COMT copies/alleles in highly polyploid sugarcane improves saccharification efficiency without compromising biomass yield. Plant Biotechnology Journal 16 (4): 856-866.

Kato-Nitta, N., T. Maeda, Y. Inagaki, and M. Tachikawa. 2019. Expert and public perceptions of gene-edited crops: Attitude changes in relation to scientific knowledge. Palgrave Commun 5: 137.

Konermann, S., P. Lotfy, N.J. Brideau, J. Oki, M.N. Shokhirev, and P.D. Hsu. 2018. Transcriptome engineering with RNA-targeting type VI-D CRISPR effectors. Cell 173: 665-676.

Koonin, E.V., and K.S. Makarova. 2019. Origins and evolution of CRISPR-Cas systems. Philosophical Transactions of the Royal Society B 374: 20180087.

Kouranova, E., K. Forbes, G. Zhao, J. Warren, A. Bartels, Y. Wu, and X. Cui. 2016. CRISPRs for optimal targeting: Delivery of CRISPR components as DNA, RNA and protein into cultured cells and single-cell embryos. Human Gene Therapy 27: 464-475.

Krishnan, S.R., and C. Mohan. 2017. Methods of sugarcane transformation. In Sugarcane biotechnology: Challenges and prospects, ed. C. Mohan, 51-60. Cham: Springer.

Lawrenson, T., O. Shorinola, N. Stacey, C. Li, L. Østergaard, N. Patron, C. Uauy, and W. Harwood. 2015. Induction of targeted, heritable mutations in barley and Brassica oleracea using RNAguided Cas9 nuclease. Genome Biology 16: 258.

LeBlanc, C., F. Zhang, J. Mendez, Y. Lozano, K. Chatpar, V.F. Irish, and Y. Jacob. 2018. Increased efficiency of targeted mutagenesis by CRISPR/Cas9 in plants using heat stress. Plant Journal 93: 377-386.

Lee, Y.G., Y.S. Jin, Y.L. Cha, and J.H. Seo. 2017. Bioethanol production from cellulosic hydrolysates by engineered industrial Saccharomyces cerevisiae. Bioresource Technology 228: 355-361.

Li, T., B. Liu, M.H. Spalding, D.P. Weeks, and B. Yang. 2012. Highefficiency TALEN-based gene editing produces disease-resistant rice. Nature Biotechnology 30 (5): 390-392.

Li, S., X. Zhang, W. Wang, X. Guo, Z. Wu, W. Du, Y. Zhao, and L. Xia. 2018b. Expanding the scope of CRISPR/Cpf1-mediated genome editing in rice. Molecular Plant 11 (7): 995-998.

Li, J., X. Zhang, Y. Sun, J. Zhang, W. Du, X. Guo, S. Li, Y. Zhao, and L. Xia. 2018a. Efficient allelic replacement in rice by gene editing: a case study of the NRT1.1B gene. Journal of Integrative Plant Biology 60 (7): 536-540.

Liang, G., H. Zhang, D. Lou, and D. Yu. 2016. Selection of highly efficient sgRNAs for CRISPR/Cas9 based plant genome editing. Scientific Reports 6: 21451.

Liang, Z., K. Chen, T. Li, Y. Zhang, Y. Wang, Q. Zhao, J. Liu, H. Zhang, C. Liu, Y. Ran, and C. Gao. 2017. Efficient DNA-free genome editing of bread wheat using CRISPR/Cas9 ribonucleoprotein complexes. Nature Communications 8: 14261.

Liang, Z., K. Chen, Y. Zhang, J. Liu, K. Yin, J. Qiu, and C. Gao. 2018. Genome editing of bread wheat using biolistic delivery of CRISPR/Cas9 in vitro transcripts or ribonucleoproteins. Nature Protocols 13: 413-430.

Lin, C.S., C.T. Hsu, L.H. Yang, L.Y. Lee, J.Y. Fu, Q.W. Cheng, F.H. Wu, H.C. Hsiao, Y. Zhang, R. Zhang, W.J. Chang, C.T. Yu, W. Wang, L.J. Liao, S.B. Gelvin, and M.C. Shih. 2017. Application of protoplast technology to CRISPR/Cas9 mutagenesis: From single-cell mutation detection to mutant plant regeneration. Plant Biotechnology Journal 16 (7): 1295-1310.

Liu, Y., P. Merrick, Z. Zhang, C. Ji, B. Yang, and S.Z. Fei. 2018. Targeted mutagenesis in tetraploid switchgrass (Panicum virgatum L.) using CRISPR/Cas9. Plant Biotechnology Journal 16: 381-393.

Liu, W., M.R. Rudis, M.H. Cheplick, R.J. Millwood, J.P. Yang, C.A. Ondzighi-Assoume, G.A. Montgomery, K.P. Burris, M. Mazarei, J.D. Chesnut, and C.N. Stewart. 2020. Lipofection-mediated genome editing using DNA-free delivery of the Cas9/gRNA ribonucleoprotein into plant cells. Plant Cell Reports 39: 245-257.

Lowe, K., E. Wu, N. Wang, G. Hoerster, C. Hastings, M.J. Cho, C. Scelonge, B. Lenderts, M. Chamberlin, J. Cushatt, L. Wang, L. Ryan, T. Khan, J. Chow-Yiu, W. Hua, M. Yu, J. Banh, Z. Bao, K. Brink, E. Igo, B. Rudrappa, P.M. Shamseer, W. Bruce, L. Newman, B. Shen, P. Zheng, D. Bidney, C. Falco, J. Register, Z.Y. Zhao, D. Xu, T. Jones, and W. Gordon-Kamm. 2016. Morphogenic regulators Baby boom and Wuschel improve monocot transformation. The Plant Cell 28: 1998-2015.

Lowe, K., M. La Rota, G. Hoerster, C. Hastings, N. Wang, M. Chamberlin, E. Wu, T. Jones, and W. Gordon-Kamm. 2018. Rapid genotype "independent" Zea mays L. (maize) 
transformation via direct somatic embryogenesis. Vitro Cellular and Developmental Biology-Plant 54: 240-252.

Lu, Y., and J.K. Zhu. 2017. Precise editing of a target base in the rice genome using a modified CRISPR/Cas9 System. Molecular Plant 10: 523-525.

Ma, X., Q. Zhu, Y. Chen, and Y.G. Liu. 2016. CRISPR/Cas9 platforms for genome editing in plants: Developments and applications. Molecular Plant 9: 961-974.

Mahfouz, M.M., and L. Li. 2011. TALE nucleases and next generation GM crops. GM Crops 2: 99-103.

Mallapaty, S. 2019. Australian gene-editing rules adopt 'middle ground'. https://www.nature.com/articles/d41586-019-01282-8.

Malnoy, M., R. Viola, M.H. Jung, O.J. Koo, S. Kim, J.S. Kim, R. Velasco, and C.N. Kanchiswamy. 2016. DNA-free genetically edited grapevine and apple protoplast using CRISPR/Cas9 ribonucleoproteins. Frontiers in Plant Science 7: 1904.

Manners, J., L. McIntyre, R. Casu, G. Cordeiro, M. Jackson, K. Aitken, P.A. Jackson, G. Bonnett, S. Lee, and R. Henry. 2004. Can genomics revolutionize genetics and breeding in sugarcane? In Proceedings of the 4th International Crop Science Congress (Brisbane, QLD)

Mao, Y., J.R. Botella, Y. Liu, and J.K. Zhu. 2019. Gene editing in plants-progress and challenges. Nature Science Reviews 6 (3): 421-437.

Meng, X., H. Yu, Y. Zhang, F. Zhuang, X. Song, S. Gao, C. Gao, and J. Li. 2017. Construction of a genome-wide mutant library in rice using CRISPR/Cas9. Molecular Plant 10 (9): 1238-1241.

Miao, C., L. Xiao, K. Hua, C. Zou, Y. Zhao, R.A. Bressan, and J.K. Zhu. 2018. Mutations in a subfamily of abscisic acid receptor genes promote rice growth and productivity. Proceedings of the National Academy of Sciences USA 115: 6058-6063.

Mishra, R., R.K. Joshi, and K. Zhao. 2020. Base editing in crops: Current advances, limitations and future implications. Plant Biotechnology Journal 18: 20-31.

Mishra, S., P.K. Singh, S. Dash, and R. Pattnaik. 2018. Microbial pretreatment of lignocellulosic biomass for enhanced biomethanation and waste management. 3 Biotech 8 (11): 458.

Mohan, C. 2016. Genome editing in sugarcane: Challenges ahead. Frontiers in Plant Science 7: 01542.

Moradpour, M., and S.N.A. Abdulah. 2020. CRISPR/dCas9 platforms in plants: Strategies and applications beyond genome editing. Plant Biotechnology Journal 18: 32-44.

Mougiakos, I., E.F. Bosma, K. Weenink, E. Vossen, K.J. Goijvaerts, J. van der Oost, and R. van Kranenburg. 2017. Efficient genome editing of a facultative thermophile using mesophilic spCas9. ACS Synthetic Biology 6: 849-861.

Nature Plants Editorial. 2018. A CRISPR definition of genetic modification. Nature Plants 4: 233.

Nishizawa-Yokoi, A., T. Cermak, T. Hoshino, K. Sugimoto, H. Saika, A. Mori, K. Osakabe, M. Hamada, Y. Katayose, C. Starker, D.F. Voytas, and S. Toki. 2015. A defect in DNA ligase 4 enhances the frequency of TALEN-mediated targeted mutagenesis in rice. Plant Physiology 170: 653-666.

Oz, M.T., A. Altpeter, R. Karan, A. Merotto, and F. Altpeter. 2021. CRISPR/Cas9-mediated multi-allelic gene targeting in sugarcane confers herbicide tolerance. Front. Genome Ed. 3: 673566. https://doi.org/10.3389/fgeed.2021.673566.

Park, J., Z.Y. Wang, C.G. Yoo, E. Dempewolf, Y. Pu, S. Debnath, A.J. Ragauskas, and P. Gilna. 2017. Defined tetra-allelic gene disruption of the 4-coumarate:Coenzyme A ligase 1 (Pv4CL1) gene by CRISPR/Cas9 in switchgrass results in lignin reduction and improved sugar release. Biotechnology for Biofuels 10: 284.

Paul, J.W., III., and Y. Qi. 2016. CRISPR/Cas9 for plant genome editing: Accomplishments, problems and prospects. Plant Cell Reports 35: 1417-1427.
Pauly, M., and K. Keegstra. 2008. Cell-wall carbohydrates and their modification as a resource for biofuels. Plant Journal 54: $559-568$.

Poovaiah, C.R., M. Nageswara-Rao, J.R. Soneji, H.L. Baxter, and C.N. Stewart. 2014. Altered lignin biosynthesis using biotechnology to improve lignocellulosic biofuel feedstocks. Plant Biotechnology Journal 12: 1163-1173.

Premachandran, M.N., P.T. Prathima, and M. Lekshmi. 2013. Sugarcane and polyploidy: A review. Journal of Sugarcane Research 1 (2): 1-15.

Puchta, H. 2017. Applying CRISPR/Cas for genome engineering in plants: The best is yet to come. Current Opinion in Plant Biology 36: $1-8$.

Puchta, H., B. Dujon, and B. Hohn. 1993. Homologous recombination in plant cells is enhanced by in vivo induction of double strand breaks into DNA by a site-specific endonuclease. Nucleic Acids Research 21: 5034-5040.

Racedo, J., L. Gutiérrez, M.F. Perera, S. Ostengo, E.M. Pardo, M.I. Cuenya, B. Welin, and A.P. Castagnaro. 2016. Genome-wide association mapping of quantitative traits in a breeding population of sugarcane. BMC Plant Biology 16 (1): 142.

Ran, F.A., P.D. Hsu, C.Y. Lin, J.S. Gootenberg, S. Konermann, A.E. Trevino, D.A. Scott, A. Inoue, S. Matoba, Y. Zhang, and F. Zhang. 2013. Double nicking by RNA-guided CRISPR Cas9 for enhanced genome editing specificity. Cell 154: 1380-1389.

Ran, F.A., L. Cong, W.X. Yan, D.A. Scott, J.S. Gootenberg, A.J. Kriz, B. Zetsche, O. Shalem, X. Wu, K.S. Makarova, E.V. Koonin, P.A. Sharp, and F. Zhang. 2015. In vivo genome editing using Staphylococcus aureus Cas9. Nature 520: 186-191.

Ran, Y., Z. Liang, and C. Gao. 2017. Current and future editing reagent delivery systems for plant genome editing. Science China Life Sciences 60: 490-505.

Rezende, C.A., M.A. Lima, P. Maziero, E.R. Azevedo, W. Garcia, and I. Polikarpov. 2011. Chemical and morphological characterization of sugarcane bagasse submitted to a delignification process for enhanced enzymatic digestibility. Biotechnology for Biofuels 4: 54.

Riaño-Pachón, D.M., and L. Mattiello. 2017. Draft genome sequencing of the sugarcane hybrid SP80-3280. F1000 Research 6: 861.

Rozov, S.M., N.V. Permyakova, and E.V. Deineko. 2019. The problem of the low rates of CRISPR/Cas9-mediated knock-ins in plants: Approaches and solutions. International Journal of Molecular Sciences 20 (13): E3371.

Sattler, S.E., and D.L. Funnell-Harris. 2013. Modifying lignin to improve bioenergy feedstocks: Strengthening the barrier against pathogens? Frontiers in Plant Science 4: 70.

Schiemann, J., J. Robienski, S. Schleissing, A. Spök, T. Sprink, and R.A. Wilhelm. 2020. Editorial: Plant genome editing - policies and governance. Frontiers in Plant Science 11: 284.

Shen, H., X. He, C.R. Poovaiah, W.A. Wuddineh, J. Ma, D.G. Mann, H. Wang, L. Jackson, Y. Tang, C.N. Stewart, F. Chen, and R.A. Dixon. 2012. Functional characterization of the switchgrass (Panicum virgatum L.) R2R3-MYB transcription factor PvMYB4 for improvement of lignocellulosic feedstocks. New Phytologist 193: 121-136.

Smargon, A.A., D.B.T. Cox, N.K. Pyzocha, K. Zheng, I.M. Slaymaker, J.S. Gootenberg, O.A. Abudayyeh, P. Essletzbichler, S. Shmakov, K.S. Makarova, E.V. Koonin, and F. Zhang. 2017. Cas $13 b$ is a Type VI-B CRISPR-associated RNA-Guided RNAse differentially regulated by accessory proteins Csx27 and Csx28. Molecular Cell 65: 618-630.

Smith, I., P.G. Greenside, T. Natoli, D.L. Lahr, D. Wadden, I. Tirosh, R. Narayan, D.E. Root, T.R. Golub, A. Subramanian, and J.G. Doench. 2017. Evaluation of RNAi and Crispr technologies by large-scale gene expression profiling in the connectivity map. PLoS Biology 15: e2003213. 
Smits, A.H., F. Ziebell, G. Joberty, et al. 2019. Biological plasticity rescues target activity in CRISPR knock outs. Nature Methods 16: 1087-1093.

Souza, G.M., H. Berges, S. Bocs, R. Casu, A. D'Hont, J.E. Ferreira, R. Henry, R. Ming, B. Potier, M.A. Van Sluys, M. Vincentz, and A.H. Paterson. 2011. The sugarcane genome challenge: Strategies for sequencing a highly complex genome. Tropical Plant Biology 4: 145-156.

Souza, G.M., M.A.V. Sluys, C.G. Lembke, H. Lee, G.R.A. Margarido, C.T. Hotta, et al. 2019. Assembly of the 373k gene space of the polyploidy sugarcane genome reveals reservoirs of functional diversity in the world's leading biomass crop. Giga Science 8: 1-18.

Soyk, S., Z.H. Lemmon, M. Oved, J. Fisher, K.L. Liberatore, S.J. Park, et al. 2017. Bypassing negative epistasis on yield in tomato imposed by a domestication gene. Cell 169: 1142-1155.e12.

Srivastava, V., J.L. Underwood, and S. Zhao. 2017. Dual-targeting by CRISPR/Cas9 for precise excision of transgenes from rice genome. Plant Cell Tissue and Organ Culture 129 (1): 153-160.

Steinert, J., S. Schiml, and H. Puchta. 2016. Homology-based doublestrand break-induced genome engineering in plants. Plant Cell Reports 35: 1429-1438.

Svitashev, S., J.K. Young, C. Schwartz, H. Gao, S.C. Falco, and A.M. Cigan. 2015. Targeted mutagenesis, precise gene editing, and site-specific gene insertion in maize using Cas9 and guide RNA. Plant Physiology 169: 931-945.

Thirugnanasambandam, P.P., N.V. Hoang, and R.J. Henry. 2018. The challenge of analyzing the Sugarcane genome. Frontiers in Plant Science 9: 616.

Toda, E., N. Koiso, A. Takebayashi, M. Ichikawa, T. Kiba, K. Osakabe, Y. Osakabe, H. Sakakibara, N. Kato, and T. Okamoto. 2019. An efficient DNA- and selectable-marker-free genomeediting system using zygotes in rice. Nature Plants 5: 363-368.

Travella, S., S.M. Ross, J. Harden, C. Everett, J.W. Snape, and W.A. Harwood. 2005. A comparison of transgenic barley lines produced by particle bombardment and Agrobacterium-mediated techniques. Plant Cell Reports 23: 780-789.

USDA. 2016. Available at https://www.ers.usda.gov/data-products/ charts-of-note/charts-of-note/?topicId=14859

Van Acker, R., J.C. Leplé, D. Aerts, V. Storme, G. Goeminne, B. Ivens, F. Légée, C. Lapierre, K. Piens, M.C.E. Van Montague, N. Santoro, C.E. Foster, J. Ralph, W. Soetaert, G. Pilate, and W. Boerjan. 2014. Improved saccharification and ethanol yield from field-grown transgenic poplar deficient in cinnamoyl-CoA reductase. Proceedings of the National Academy of Sciences USA 111: 845-850.

Vicentini, R., A. Bottcher, S.M.S. Brito, A.B. Dos Santos, S. Creste, M.G.A. Landell, I. Cesarino, and P. Mazzafera. 2015. Largescale transcriptome analysis of two sugarcane genotypes contrasting for lignin content. PLoS ONE 10: e0134909.

Waclawovsky, A.J., P.M. Sato, C.G. Lembke, P.H. Moore, and G.M. Souza. 2010. Sugarcane for bioenergy production: An assessment of yield and regulation of sucrose content. Plant Biotechnology Journal 8: 263-276.

Waltz, E. 2016. Gene-edited CRISPR mushroom escapes US regulation. Nature 532: 293.

Waltz, E. 2018. With a free pass, CRISPR-edited plants reach market in record time. Nature Biotechnology 36: 6-7.

Waterworth, W.M., G.E. Drury, C.M. Bray, and C.E. West. 2011. Repairing breaks in the plant genome: The importance of keeping it together. New Phytologist 192: 805-822.

Watson, A., S. Ghosh, M.J. Williams, W.S. Cuddy, J. Simmonds, M.D. Rey, M.A.M. Hatta, A. Hinchliffe, A. Steed, D. Reynolds, N.M. Adamski, A. Breakspear, A. Korolev, T. Rayner, L.E. Dixon, A. Riaz, W. Martin, M. Ryan, D. Edwards, J. Batley, H. Raman, J. Carter, C. Rogers, C. Domoney, G. Moore, W.
Harwood, P. Nicholson, M.J. Dieters, I.H. DeLacy, J. Zhou, C. Uauy, S.A. Boden, R.F. Park, B.B.H. Wulff, and L.T. Hickey. 2018. Speed breeding is a powerful tool to accelerate crop research and breeding. Nature Plants 41: 23-29.

Wiedenheft, B., S.H. Sternberg, and J.A. Doudna. 2012. RNA-guided genetic silencing systems in bacteria and archaea. Nature 482: 331-338.

Wolter, F., and H. Puchta. 2017. Knocking out consumer concerns and regulator's rules: Efficient use of CRISPR/Cas ribonucleoprotein complexes for genome editing in cereals. Genome Biology 18 (1): 43.

Wolter, F., and H. Puchta. 2018. The CRISPR/Cas revolution reaches the RNA world: Cas13, a new Swiss Army knife for plant biologists. Plant Journal 94: 767-775.

Wolter, F., P. Schindele, and H. Puchta. 2019. Plant breeding at the speed of light: The power of CRISPR/Cas to generate directed genetic diversity at multiple sites. BMC Plant Biology 19 (1): 176.

Woo, J.W., J.K. Kim, and S.I. won, C. Corvalán, S.W. Cho, H. Kim, S.G. Kim, S.T. Kim, S. Choe, and J.S. Kim. . 2015. DNA-free genome editing in plants with preassembled CRISPR-Cas9 ribonucleoproteins. Nature Biotechnology 33: 1162-1164.

Wu, H., F.S. Awan, A. Vilarinho, Q. Zeng, B. Kannan, T. Phipps, J. McCuiston, W. Wang, K. Caffall, and F. Altpeter. 2015. Transgene integration complexity and expression stability following biolistic or Agrobacterium-mediated transformation of sugarcane. Vitro Cellular and Developmental Biology Plant 51: 603-611.

Yan, W.X., S. Chong, H. Zhang, K.S. Makarova, E.V. Koonin, D.R. Cheng, and D.A. Scott. 2018. Cas13d is a compact RNAtargeting type VI CRISPR effector positively modulated by a WYL-domain-containing accessory protein. Molecular Cell 70: 327-339.

Yang, H., J.J. Wu, T. Tang, K.D. Liu, and C. Dai. 2017. CRISPR/ Cas9-mediated genome editing efficiently creates specific mutations at multiple loci using one sgRNA in Brassica napus. Scientific Reports 7: 1-13.

Yau, Y.Y., and M. Easterling. 2019. Lignocellulosic feedstock improvement for biofuel production through convertional breeding and biotechnology. In: Biofels: Greenhouse Gas Mitigation and Global Warming, pp 107-140 Springer-Next Generation Biofuels and Role of Biotechnoloogy

Yeh, S.Y., F.C. Huang, T. Hoffmann, M. Mayershofer, and W. Schwab. 2014. FaPOD27 functions in the metabolism of polyphenols in strawberry fruit (Fragaria sp.). Frontier in Plant Science 5: 518.

Yin, K., T. Han, G. Liu, T. Chen, Y. Wang, A.Y. Yu, and Y. Liu. 2015. A geminivirus-based guide RNA delivery system for CRISPR/Cas9 mediated plant genome editing. Scientific Reports 5: 14926.

Yin, K., T. Han, and Y. Liu. 2017. Use of geminivirus for delivery of CRISPR/Cas9 components to tobacco by Agro-infiltration. BioProtocol. https://doi.org/10.21769/BioProtoc.2209.

Yuan, J.S., K.H. Tiller, H. Al-Ahmad, N.R. Stewart, and C.N. Stewart. 2008. Plants to power: Bioenergy to fuel the future. Trends in Plant Science 13: 421-429.

Yuen, G., F.J. Khan, S. Gao, J.M. Stommel, E. Batchelor, X. Wu, and J. Luo. 2017. CRISPR/Cas9-mediated gene knockout is insensitive to target copy number but is dependent on guide RNA potency and Cas9/sgRNA threshold expression level. Nucleic Acids Research 45 (20): 12039-12053.

Zaidi, S.S., and S. Mansoor. 2017. Viral vectors for plant genome engineering. Frontiers in Plant Science 8: 539.

Zaidi, S.S., M.M. Mahfouz, and S. Mansoor. 2017. CRISPR-Cpf1: A new tool for plant genome editing. Trends in Plant Science 22 (7): $550-553$. 
Zetsche, B., J.S. Gootenberg, O.O. Abudayyeh, I.M. Slaymaker, K.S. Makarova, P. Essletzbichler, S.E. Volz, J. Joung, J. van der Oost, A. Regev, E.V. Koonin, and F. Zhang. 2015. Cpf1 is a single RNA-guided endonuclease of a Class 2 CRISPR-Cas system. Cell 163: 759-771.

Zhang, H., J. Zhang, P. Wei, B. Zhang, F. Gou, Z. Feng, Y. Mao, L. Yang, H. Zhang, N. Xu, and J.K. Zhu. 2014. The CRISPR/Cas9 system produced specific and homozygous targeted gene editing in rice in one generation. Plant Biotechnology Journal 12: 797-807.

Zhang, J.P., X.L. Li, A. Neises, W. Chen, L.P. Hu, G.Z. Ji, J.Y. Yu, J. Xu, W.P. Yuan, T. Cheng, and X.B. Zhang. 2016. Different effects of sgRNA length on CRISPR-mediated gene knockout efficiency. Scientific Reports 6: 28566.

Zhang, Q., H.L. Xing, Z.H. Wang, Z.Y. Zhang, F. Yang, X.C. Wang, and Q.J. Chen. 2018a. Potential high-frequency off-target mutagenesis induced by CRISPR/Cas9 in Arabidopsis and its prevention. Plant Molecular Biology 96: 445-456.

Zhang, J., X. Zhang, H. Tang, Q. Zhang, X. Hua, X. Ma, F. Zhu, T. Jones, X. Zhu, J. Bowers, et al. 2018b. Allele-defined genome of the autopolyploid sugarcane Saccharum spontaneum L. Nature Genetics 50 (11): 1565-1573.

Zhang, Y., A.A. Malzahn, S. Sretenovic, and Y. Qi. 2019. The emerging and uncultivated potential of CRISPR technology in plant science. Nature Plants 5: 778-794.
Zhao, Y., C. Zhang, W. Liu, W. Gao, C. Liu, and G. Song. 2016. An alternative strategy for targeted gene replacement in plants using a dual-sgRNA/Cas9 design. Scientific Reports 6: 23890.

Zhao, C., X. Zheng, W. Qu, G. Li, X. Li, Y.L. Miao, X. Han, X. Liu, Z. Li, Y. Ma, Q. Shao, H. Li, F. Sun, S. Xie, and S. Zhao. 2017. CRISPR-offinder: A CRISPR guide RNA design and off-target searching tool for user-defined protospacer adjacent motif. International Journal of Biological Sciences 13: 1470-1478.

Zheng, Y., N. Zhang, G.B. Martin, and Z. Fei. 2019. Plant genome editing database (PGED): A call for submission of information about genome-edited plant mutants. Molecular Plant 12 (2): $127-129$.

Zhou, X., T.B. Jacobs, L.J. Xue, S.A. Harding, and C.J. Tsai. 2015. Exploiting SNPs for biallelic CRISPR mutations in the outcrossing woody perennial Populus reveals 4-coumarate:CoA ligase specificity and redundancy. New Phytologist 208: 298-301.

Zuo, E., X. Huo, X. Yao, X. Hu, Y. Sun, J. Yin, et al. 2017. CRISPR/ Cas9-mediated targeted chromosome elimination. Genome Biology 18: 224.

Publisher's Note Springer Nature remains neutral with regard to jurisdictional claims in published maps and institutional affiliations. 